\title{
A Climatology of Rain-on-Snow Events for Norway ${ }^{0}$
}

\author{
Pardeep Pall, Lena M. Tallaksen, And Frode Stordal \\ Department of Geosciences, University of Oslo, Oslo, Norway
}

(Manuscript received 15 August 2018, in final form 27 June 2019)

\begin{abstract}
Rain-on-snow (ROS) events are multivariate hydrometeorological phenomena that require a combination of rain and snowpack, with complex processes occurring on and within the snowpack. Impacts include floods and landslides, and rain may freeze within the snowpack or on bare ground, potentially affecting vegetation, wildlife, and permafrost. ROS events occur mainly in high-latitude and mountainous areas, where sparse observational networks hinder accurate quantification - as does a scale mismatch between coarse-resolution $(50-100 \mathrm{~km})$ reanalysis products and localized events. Variability in the rain-snow temperature threshold and temperature sensitivity of snowmelt adds additional uncertainty. Here the high-resolution $(1 \mathrm{~km}) \mathrm{se}-$ Norge hydrometeorological dataset, capturing complex topography and drainage networks, is utilized to produce the first large-scale climatology of ROS events for mainland Norway. For daily data spanning 1957-2016, suitable rain and snowpack thresholds for defining ROS events are applied to construct ROS climatologies for 1961-90 and 1981-2010 and to investigate trends. Differing ROS characteristics are found, reflecting Norway's diverse climates. Relative to 1961-90, events in the 1981-2010 period decrease most in the southwest low elevations in winter, southeast in spring, and north in summer (consistent with less snow cover in a warming climate) and increase most in the southwest high elevations, central mountains, and north in winter-spring (consistent with increased precipitation and/or more snow falling as rain in a warming climate). Winter-spring events also broadly correlate with the North Atlantic Oscillation, and the Scandinavia pattern - and more so with the Arctic Oscillation, particularly in the southern mountain region where long-term ROS trends are significant $(+0.50$ and +0.33 daily ROS counts per kilometer squared per decade for winter and spring).
\end{abstract}

\section{Introduction}

While numerous studies exist on extreme rain events (Hartmann et al. 2013), studies of rain-on-snow (ROS) events are less commonplace-in part because they occur mainly in high-latitude and mountainous areas (e.g., Ye et al. 2008; Hansen et al. 2014; McCabe et al. 2007; Beniston and Stoffel 2016). However, ROS events can also be extreme, if somewhat more complex, hydrometeorological phenomena requiring a sufficient combination of rain, snowpack, and snow cover to generate high-impact events. Furthermore, each of these components need not necessarily be extreme in themselves to generate an impact. Nor do the components have to form simultaneously-such as when spring rain falls on

\footnotetext{
Supplemental information related to this paper is available at the Journals Online website: https://doi.org/10.1175/JCLI-D-180529.s1.
}

Corresponding author: Pardeep Pall, pardeep.pall@geo.uio.no snow that has persisted on the ground since its formation in winter. Thus surface temperature and elevation are also a modulating factor (e.g., Würzer et al. 2016), all adding to the complexity.

The impacts of ROS events are also complex, with most immediate impacts including floods, landslides, and snow avalanches, which result from a combination of rain and snowmelt (e.g., Marks et al. 1998; Harr 1981; Stimberis and Rubin 2011). However, there can also be longer-term impacts, such as when fallen rain subsequently percolates and freezes within the snowpack, forming ice layers that can affect vegetation growth or produce "locked pastures" that inhibit animals from foraging; with surface temperature being an important factor (Putkonen et al. 2009; Hansen et al. 2014). Furthermore, the latent heat released upon freezing of rain can ripen the snowpack, making it susceptible to future rain; deep-percolating rain and any subsequent ground ice formation can also affect the thermal budget of permafrost (Putkonen and Roe 2003; Westermann et al. 2011). Thus it is of value to understand the 
climatology of ROS events and how it might be affected by climate change.

This complexity of ROS events and associated impacts, however, has led to varying definitions for their quantification. Most studies require, at the very least, minimum daily thresholds for both rain and snowpack [typically characterized by its snow water equivalent (SWE), or snow depth] to be exceeded for an ROS event (on a daily time scale) to occur, but this can be augmented to include a snowmelt component if flooding is the focus (see, e.g., Freudiger et al. 2014, and references therein). Furthermore, the thresholds can be region and impact specific-for example, rain thresholds are typically higher for alpine regions, reflecting the overall larger snowpacks in the region and thus larger amount of rain needed for flooding to occur (Beniston and Stoffel 2016; Würzer et al. 2016). Other more general studies make more flexible definitions dictated by multiple impacts; for example, Rennert et al. (2009) chose a low and high threshold for the rain component, reflecting the smaller-scale impact on foraging ungulates and the larger-scale impact on permafrost in the Arctic, respectively. In regions, such as the high Arctic, with continuous winter-spring snow cover, all rain events may be considered ROS events (Hansen et al. 2014), and this point may also apply in high-altitude regions. Additionally, the data product used to measure ROS components can itself dictate the definition. For example, if precipitation observations do not distinguish between rain and snowfall, then an additional criteria for an ROS event can be that SWE must decrease on successive days (Jeong and Sushama 2018); a simple temperature-based criterion may also be used to distinguish between rain and snow (Beniston and Stoffel 2016), although the same temperature threshold may not be applicable across all regions (Jennings et al. 2018).

Field investigations (e.g., Singh et al. 1997; Floyd and Weiler 2008; Garvelmann et al. 2014; Trubilowicz and Moore 2017) and case studies (Marks et al. 1998; Sui and Koehler 2001; Pomeroy et al. 2016; Pradhanang et al. 2013; Hansen et al. 2014; Morán-Tejeda et al. 2016; Corripio and López-Moreno 2017) can offer good insight into the interplay between components of an ROS event, and serve as a bell weather for future changes. However, comprehensive large-scale studies are hindered by typically sparse observation networks in highlatitude and mountainous regions, and studies based on global reanalysis suffer from a mismatch between the coarse resolution of the products $(\sim 50-100 \mathrm{~km})$ and the finerscale of actual events. Accordingly, only general conclusions can be drawn, with more focus on the driving atmospheric circulation patterns (Rennert et al. 2009; Cohen et al. 2015). Thus, few high-resolution large-scale ROS studies exist to date, and they are generally on the order of a few tens of kilometers squared at best (e.g., McCabe et al. 2007; Freudiger et al. 2014; Jeong and Sushama 2018).

In this study we construct a large-scale ROS climatology over all of mainland Norway for recent decades by taking advantage of an observationally derived highresolution $(1 \mathrm{~km}$, daily) gridded hydrometeorological dataset: "seNorge" (Tveito et al. 2005). This dataset was utilized recently by Rizzi et al. (2018, hereinafter R18), to explore the effect of rising temperatures over recent decades on snow cover. They found that snow cover generally decreased, notably in spring and early summer. However, there were interesting regional variations according to the "macroregions" they used, reflecting the various climates in Norway. These climates range from northern Arctic, to central alpine, to southern maritime. In this sense, Norway provides an interesting "laboratory" for examining potential changes in regional characteristics of ROS events over recent decades, and so our study can also provide insight transferable to similar climates in other parts of the world.

We thus focus on aggregate ROS characteristics of the 1-km data over the same macroregions used in R18. By aggregating we also mitigate for the effective resolution of the dataset possibly being less than $1 \mathrm{~km}$ (see section 2a). This is the first time, to our knowledge, that an ROS climatology has been constructed specifically for mainland Norway. Cruder-resolution studies for the Northern Hemisphere have previously been performed using reanalysis (e.g., Putkonen and Roe 2003; Cohen et al. 2015), and do at least suggest a general winter ROS signal over Norway for past years. Furthermore, studies showing recent changes in heavy precipitation (Dyrrdal et al. 2012) and winter warming episodes (VikhamarSchuler et al. 2016) for some Norwegian regions, along with broader increases in precipitation and temperature (Hanssen-Bauer et al. 2015), do at least indicate that the risk of ROS events could have increased in some regions and seasons-and they are certainly a known major trigger of floods and other impacts (e.g., landslides and slush flows) in the country (Roald 2013; Hansen et al. 2014; Hanssen-Bauer et al. 2015). We also examine the relationship to large-scale circulation indices, to provide a broader context.

\section{Data and methods}

\section{a. The seNorge dataset}

seNorge is a high-resolution gridded hydrometeorological dataset covering mainland Norway (Tveito et al. 2005). It is produced by taking station observations of 
temperature and precipitation from the Norwegian Meteorological Office observation network and optimally interpolating to a 1-km grid; this subsequently drives an operational hydrological model from the Norwegian Water and Energy Directorate (NVE), which generates snow variables such as SWE, snow depth, and snow-cover area (SCA), on the same grid. An overview of seNorge is found in Dyrrdal et al. (2012) and R18. They outline the gridding procedure based on the observations at stations, which populate higherelevation areas less densely than lower-elevation areas. The procedure involves a location-dependent residual kriging approach for temperature stations, and irregular triangular networks for precipitation stations that account for elevation. Precipitation is first corrected for undercatch and then partitioned into rain and snowfall according to the gridded temperature, if rain and snowfall are not measured separately. The gridded temperature and precipitation are fed into the NVE hydrological model whose degree-day based snow modules compute SWE from snowpack water balance, and then snow depth based on compaction of SWE. The overview also discusses the limitations of the dataset-related mainly to interpolation of variables over complex topography, lack of data homogeneity due to sparser observation networks at higher elevations, precipitation undercatch, and change in the number of observing stations over time. The lack of station homogeneity, in particular, can mean that the effective resolution of the information in the dataset is not $1 \mathrm{~km}$, despite the interpolation procedures. This is one reason why in this study we instead focus on ROS characteristics using the $1-\mathrm{km}$ data aggregated over much larger macroregions (see section $2 \mathrm{c}$ ).

We also note that updated versions of the dataset are currently under development, particularly in terms of improving mountainous precipitation issues, but new releases, including snow variables, are not planned until later in 2019 (C. Lussana, NVE, 2019, personal communication). For this reason we chose to use version 1 of the dataset, as also used in R18. Specifically, we use version 1.1 (Mohr 2009) for the meteorological variables of temperature and precipitation. The latter was apportioned into rain and snowfall using a temperature threshold of $0.5^{\circ} \mathrm{C}$ as a general value, applicable over a large scale across Norway (Saloranta 2012). This threshold has also been used previously in a study of rainfall versus snowmelt-driven floods across Norway (Vormoor et al. 2016)_albeit it may not be applicable at smaller scales (Jennings et al. 2018). We use version 1.1.1 of the snow model (Saloranta 2014) for the snow variables of SWE and SCA, where this model has improved routines for snowmelt, accumulation, and distribution, compared to that of the original model (Saloranta 2012). Data are available from September 1957 to present, at daily resolution, and here we consider data up to November 2016.

\section{b. ROS definition}

Following conventional approaches, we define an ROS event based on daily rain and SWE thresholds both being exceeded. Specifically, an ROS event occurs in each grid square of our dataset on a day with at least $3 \mathrm{~mm}$ of SWE, and at least $5 \mathrm{~mm}$ of rain. This choice is based mainly on the broad analysis of Rennert et al. (2009), and constitutes values generally applicable across a range of hydroclimates. In particular, we chose $5 \mathrm{~mm}$ as an intermediate threshold for rain, possibly most adapted to flood impacts, as the value lies in between the values affecting foraging animals $(3 \mathrm{~mm})$, and permafrost $(10 \mathrm{~mm})$, according to Rennert et al. (2009). Specifically, we reason that, on a daily time scale and across a range of hydroclimates (as found in Norway), flood-inducing ROS events would generally involve rain heavier than $3 \mathrm{~mm}$, but not necessarily heavier than $10 \mathrm{~mm}$. We additionally require at least $25 \%$ daily SCA per grid square to mask out relatively small events. Choosing harsher criteria $(\mathrm{SWE}=5 \mathrm{~mm}$, rain $=10 \mathrm{~mm}$, and $\mathrm{SCA}=50 \%$ ), as found partly in some studies (e.g., Cohen et al. 2015), did not qualitatively affect our results (see Figs. S1-S3 in the online supplemental material), and some large-scale studies have even used more lax criteria (e.g., Jeong and Sushama 2018).

\section{c. Study regions}

Following R18, we conduct our analysis over four macroregions in mainland Norway covering different climates and elevations (Fig. 1). These regions are derived from smaller climatic regions in Norway (Dyrrdal et al. 2012). By using the same four macroregions as in R18 (and the same dataset), we can also leverage the results from that study with regard to observed temperature, precipitation, and snow to inform our findings for rain on snow. The climate characteristics for each macroregion are described as follows:

1) The south-central "Mountain" region is demarcated using the first $1000 \mathrm{~m}$ MSL line encountered relative to the coasts; areas within the region such as valleys can still be below $1000 \mathrm{~m}$ MSL. It has an alpine climate partially influenced by westerly Atlantic flows. This region is dominated by a complex mountain range that together with an extended, but less prominent, range continuing farther northward, spans several latitudes. This topographic feature to 


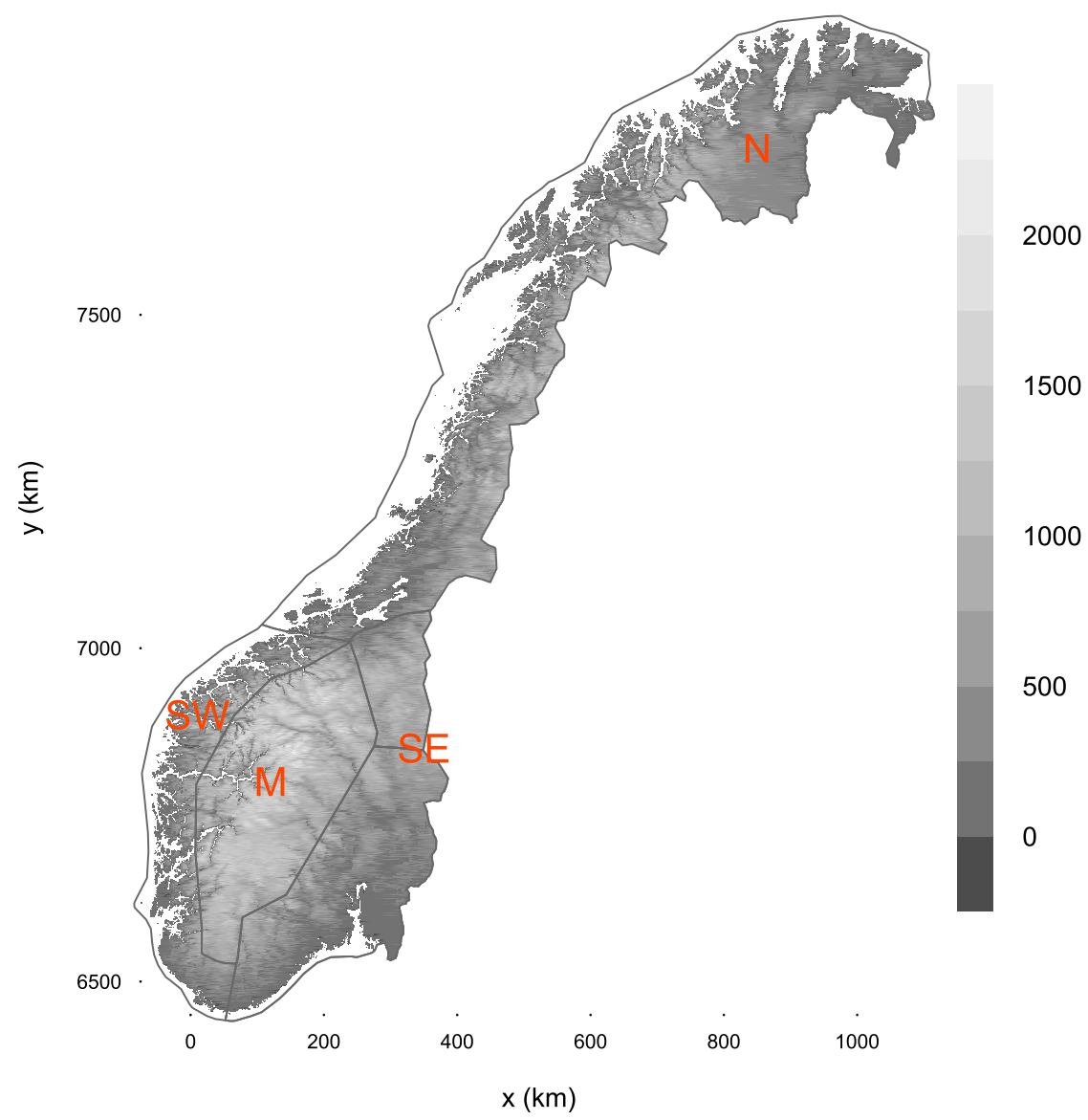

FIG. 1. Elevation (m) for mainland Norway in the seNorge dataset, on the universal transverse Mercator zone $33 \mathrm{~N}$ projection used throughout this study. The four macroregions considered in this study are demarcated by the gray borders and labeled by the red symbols as follows: $\mathrm{M}=$ Mountain, $\mathrm{N}=$ North, $\mathrm{SW}=$ Southwest, and SE = Southeast. Note that the SE macroregion actually comprises two subregions, as a legacy of their original definition (see R18), that are considered as one throughout this study.

a large part influences Norwegian weather on both the western coastline and eastern inland (see the other region descriptions below), and the region itself receives large amounts of precipitation from incoming low pressure systems (Dyrrdal et al. 2012). The precipitation often falls as snow in higherelevation areas (on average, approximately $30 \%$ of the annual precipitation falls as snow; Saloranta 2014), and its distribution is complex reflecting the sharp gradients in topography (Dyrrdal et al. 2013), meaning that snow can persist for large parts of the year in some locations [snow cover above $800 \mathrm{~m}$ in southern Norway is present for at least 200 days of the year during the period 1971-2000, according to Hanssen-Bauer et al. (2015)]. This also means high discharge during spring and early summer due to snowmelt (and even glacier melt in late summer) (Vormoor et al. 2016).
2) The "Southwest" region has a mild wet maritime climate dominated by southwesterly Atlantic flows. Most precipitation in this region originates from moist flows from the Atlantic Ocean that collide with the steep central mountain range, resulting in heavy orographically driven events, and an annual mean of more than $3500 \mathrm{~mm}$ in some parts (Dyrrdal et al. 2012; Vormoor et al. 2016). The year-to-year variability in Atlantic storminess is also reflected in the annual precipitation, which deviates by up to $\pm 30 \%$ from the $1971-2000$ baseline (Hanssen-Bauer et al. 2015). The highest precipitation occurs during fall and winter, as also reflected in discharge-with rain rather than snowmelt being the main runoff generating process in this milder southern climate (Vormoor et al. 2016). In fact, with mean annual temperatures of more than $6^{\circ} \mathrm{C}$, as compared with less than $-3^{\circ} \mathrm{C}$ in the high-elevation areas of the 
Mountain region (Vormoor et al. 2016), the southern coast has the lowest climatological (1961-90) annual SWE values $(<100 \mathrm{~mm})$ in Norway, although these values increase toward the foothills (R18).

3) The "Southeast" region also has a maritime climate in the south but is somewhat sheltered from westerly flows by the Mountain region. Accordingly, the inner parts of the Southeast region are characterized by a drier and colder continental climate (Dyrrdal et al. 2013). These inland regions receive the largest precipitation during summer (Vormoor et al. 2016). This can include convective precipitation that extends from the southern coast (Dyrrdal et al. 2018), which still experiences a somewhat maritime coastal climate associated with more southerly, and to a lesser extent easterly, moist continental flows (Roald 2008).

4) The "North" region has a predominantly Arctic climate. However, there is some influence of warmer westerly flows at the coasts, particularly farther south, akin to the Southwest region (Dyrrdal et al. 2013). Higher-elevation areas along the spine of the North region share some of the snow and runoff characteristics with the southern central Mountain region (Vormoor et al. 2016). These high-elevation areas also shelter the far northeast part of the region that, akin to inland areas of the Southeast region, experiences a dry and cold continental winter climate, where mean annual precipitation is as low as $300 \mathrm{~mm}$ (Vormoor et al. 2016).

\section{d. Analysis methods}

We primarily analyze ROS characteristics by constructing two long-term climatologies. First, we construct a 30-yr-average monthly climatology of daily ROS events for 1961-90, which serves as our baseline (presented in section 3a). Second, we construct a corresponding 30-yr climatology for 1981-2010, which we compare to our baseline to investigate ROS changes (presented in section $3 b$ ). These results are presented on nationwide maps (mainland only) and also as averages over the four study regions. They are also presented according to five elevation bands $(<500,500 \leq$ $1000,1000 \leq 1500,1500 \leq 2000$, and $>2000 \mathrm{~m})$, to better understand the elevations at which ROS events occur.

Furthermore, we investigate the time series of ROS events over the whole data period (September 1957November 2016) and split these by region and season (presented in section 3b). Seasons are defined as December-February for winter, March-May for spring, June-August for summer, and September-November for fall. A trend is fitted to these time series using the Theil-Sen estimator (Theil 1950; Sen 1968), which is a nonparametric method for trend detection that is widely applied to hydrometeorological time series. The ROS time series are also tested for normality and found to be nonnormally distributed for the vast majority of the mainland (not shown). Thus, trend significance is estimated (at the 5\% level) using the nonparametric Mann-Kendall test, suited to hydrometeorological data because they are typically nonnormally distributed and so not suited to other slope-based tests such as the parametric $t$ test that assumes normality of the underlying data (Yue and Pilon 2004).

To gain a broader perspective of ROS characteristics and their relation to the large-scale atmospheric circulation, we correlate our nationwide ROS counts against three established indices representing dominant modes of atmospheric variability known to influence northern European weather (presented in section 3c). First, we correlate against the North Atlantic Oscillation index (NAOi), for which a positive index is associated with wetter winter weather funneled into northern Europe by pressure centers in the Atlantic, accompanied by drier weather in southern Europe (Hurrell et al. 2003). The opposite is true for a negative NAOi. Second, we correlate against the Arctic Oscillation index (AOi), which is akin to the NAOi in its characteristics, but represents circulation more annular about the North Pole in nature. It is dictated by pressure centers more symmetric about the Arctic, given that it is a lower atmospheric manifestation of the polar vortex (Thompson and Wallace 1998). While the NAOi and AOi are two of the most influential indices for European ROS occurrence (Cohen et al. 2015), we also correlate our ROS counts against the Scandinavia circulation index (SCAi), whose atmospheric circulation pattern can have an influence on weather more local to Norway (e.g., Bueh and Nakamura 2007). This index is associated with the propagation of a Rossby wave train from the Atlantic to higher European latitudes and into northern Eurasia, with the primary center of action around the Scandinavian Peninsula. A positive index is associated with a high pressure blocking system over the peninsula and dry conditions (Bueh and Nakamura 2007). The opposite is true for a negative SCAi.

Values of monthly NAOi, AOi, and SCAi were downloaded from the U.S. National Centers for Environmental Information (NOAA/CPC 2019a, NOAA/CPC 2019b, and NOAA/CPC 2019c, respectively) and averaged to seasonal values. Note that the NAOi and SCAi values are available as standardized values but the AOi values are not, and therefore the latter were standardized after 
downloading. Correlations between ROS counts and the circulation indices are assessed using Spearman's rank correlation coefficient (Spearman 1904) throughout the analysis, as this is suited to nonnormally distributed data. Nationwide maps of correlation are produced and areas of correlation significant at the $1 \%$ level are identified.

We use two techniques to assess how changes/trends in ROS may be related to changes/trends in the circulation indices. First, we produce scatterplots of ROS versus the circulation indices for all four macroregions. This allows us to visualize the nature of any relationship between the two variables, and identify years where particularly large changes in two variables are related. Second, we follow the method of Irannezhad et al. (2017) and correlate long-term time series of ROS and circulation indices to see which index is the most influential on that trend.

\section{Results}

\section{a. Baseline ROS climatology (1961-90)}

Our baseline 1961-90 ROS climatology is displayed via maps in Fig. 2 and via elevation bands in Fig. 3 and Figs. S4-S7 in the online supplemental material. Throughout winter-spring (December-May), and especially in the early winter months (DecemberJanuary), ROS events occur most frequently in the Southwest region (Fig. 2). They also occur most frequently in low-elevation areas across the mainland (Fig. 3) by virtue of there being a larger land area at these low elevations, so that the North and Southwest regions contribute the most to these counts (Figs. S5 and S6 in the online supplemental material). The Southwest region very much dominates in terms of ROS activity during these months when compared with the other regions, as summarized in Fig. 4a. In particular, many ROS events also occur at higher-elevation areas of the Southwest region (Fig. S6), which form the foothills of the more mountainous central Norway (see section 2c). In fact, there is some continuation of the high frequency of ROS events into the western flank of the Mountain region during winter, also reflected in the elevation analysis (Fig. S4 in the online supplemental material). A similar pattern is found for the western flank of high-elevation areas in the North region. Related to this, a rain shadow-type pattern is apparent in the Southeastern region on the eastern side of the Mountain region. Here ROS activity occurs later in the spring (particularly in April/May, as illustrated by the peak in Fig. $4 \mathrm{a}$ and the $500-1000-\mathrm{m}$ elevation band in supplemental Fig. S7).
From late spring to early summer (May-July), ROS events dominate the Mountain region (Fig. 2) and, to some extent, high-elevation areas of the neighboring Southwest and Southeast regions (Figs. S4, S6, and S7 in the online supplemental material). They also dominate high-elevation areas of the North region (supplemental Fig. S5). This is most clearly seen in Fig. 4a, where ROS counts for the Mountain and North regions are at a peak during this period relative to the rest of the year. After June/July, little ROS activity is found in all four regions (all curves are at a minimum in Fig. 4a) until the snow season begins again in October/ November-with the signal generally appearing first in the higher-elevation areas of Norway.

\section{b. Change relative to baseline ROS climatology (1981-2010 vs 1961-90)}

Our 1981-2010 ROS climatology is compared with our baseline 1961-90 climatology via maps in Fig. 5 and via elevation bands in Fig. 6 and Figs. S8-S11 in the online supplemental material. Winter-spring is the most active period (Fig. 5). There are generally increases at all elevations when ROS counts are aggregated across the mainland (Fig. 6), with all macroregions contributing except notably the Southwest (Fig. S10 in the online supplemental material). That region exhibits mixed changes, with decreases in ROS events in coastal areas (peaking in December/January and April/May), and increases in the higher-elevation foothill areas (particularly in January-February). These increases dominate the regional-average change, as seen in Fig. 4b. They also continue into the western flank of the Mountain region, with a strong signal in January-April (Fig. 5 and Fig. S8 in the online supplemental material). A similar signal is found for the North region for December-May. Minor changes are seen in late summer and fall in all regions.

In late spring, and particularly in May, notable ROS decreases are found in the Southeast region, both in coastal and higher-elevation areas (Fig. 5 and Fig. S11 in the online supplemental material). This behavior is similar to the winter-spring decrease in the Southwest region (cf. the May minima in Fig. 4b). Summer (particularly June) exhibits ROS declines in the North region, along with small areas of ROS increase in the highest-elevation areas of the Mountain region. From August onward, very little ROS change occurs in all regions, reflecting the low frequency of ROS events in the baseline climate until the start of the following snow season.

The above changes also manifest somewhat in annual time series constructed over the whole data period, with ROS counts averaged over each region and summed by season (Fig. 7). Again we see that large ROS counts 
Dec
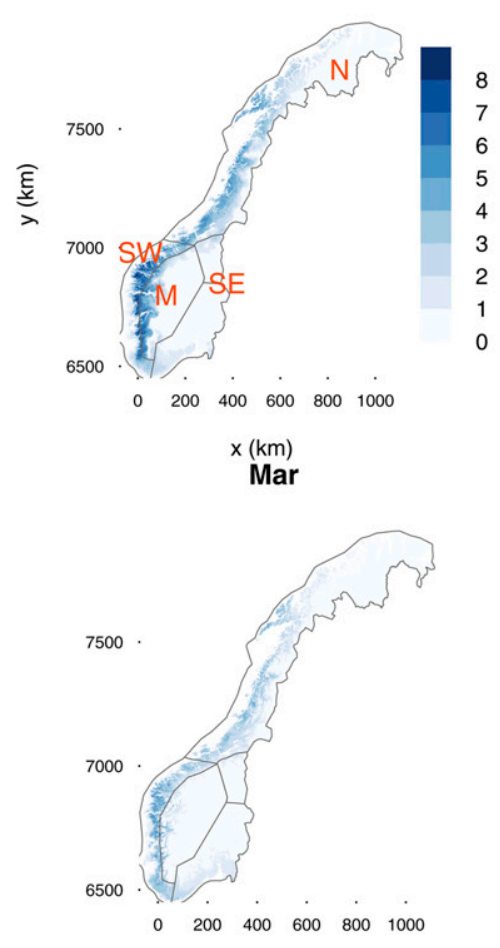

Jun

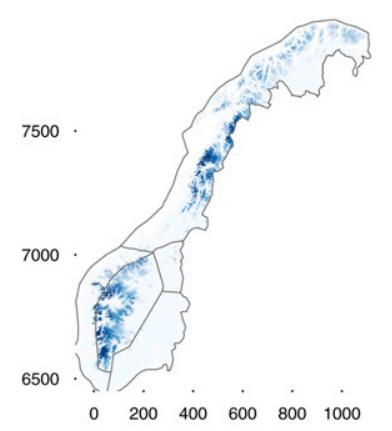

Sep

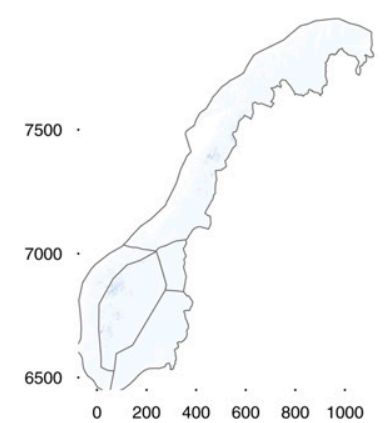

Jan

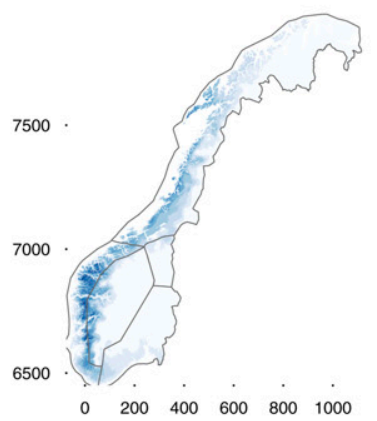

Apr

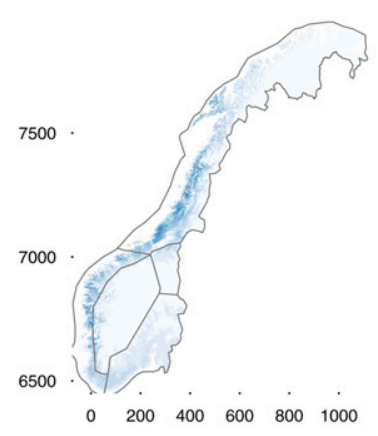

Jul

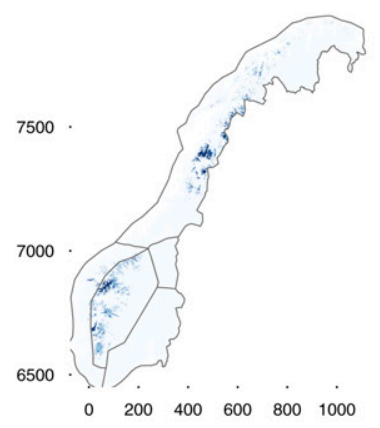

Oct

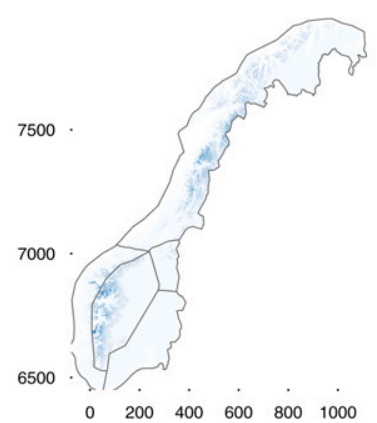

Feb

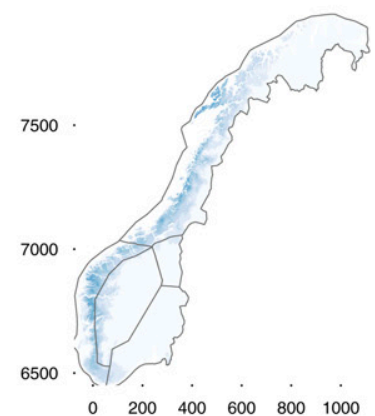

May

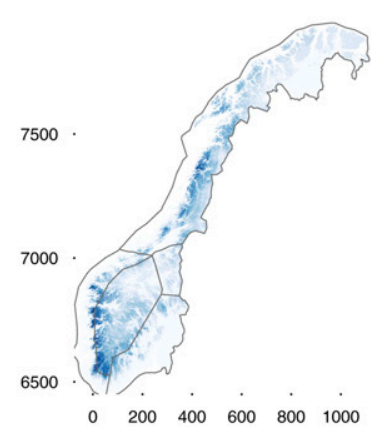

Aug

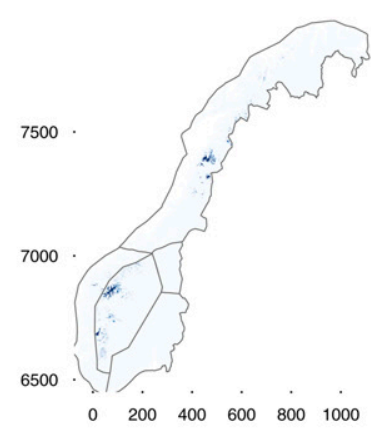

Nov

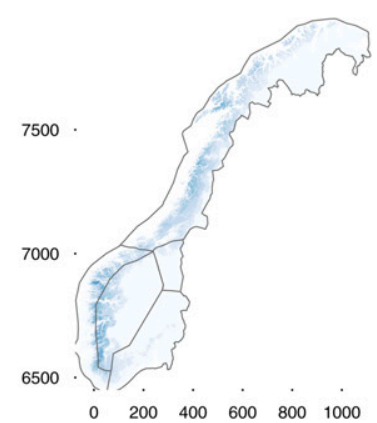

FIG. 2. Average monthly counts of daily ROS events for the period 1961-90. The four macroregions are as shown in Fig. 1. 
Dec

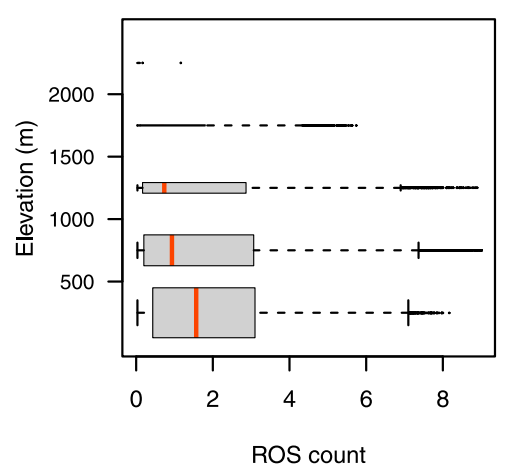

Mar

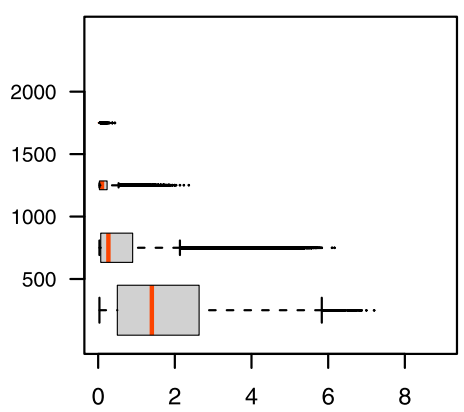

Jun

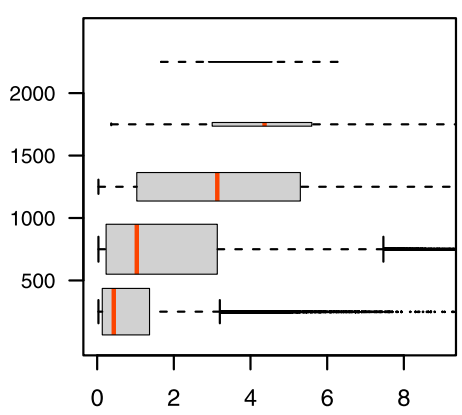

Sep

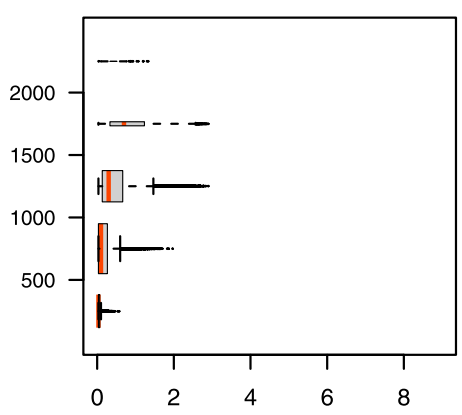

Jan

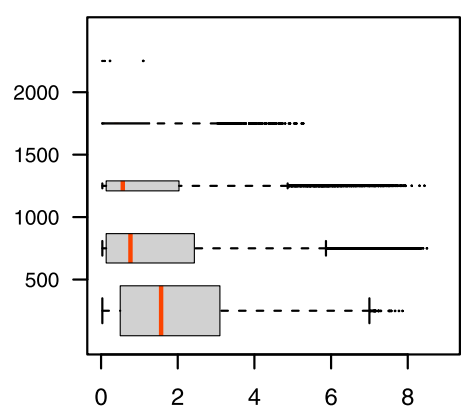

Apr

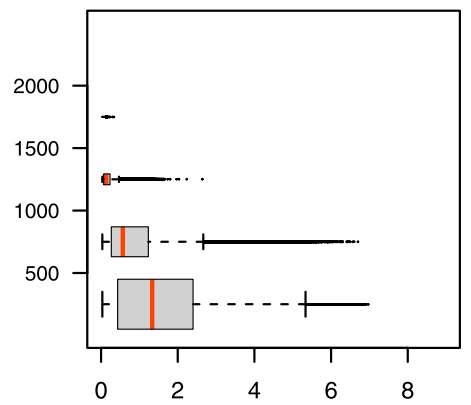

Jul

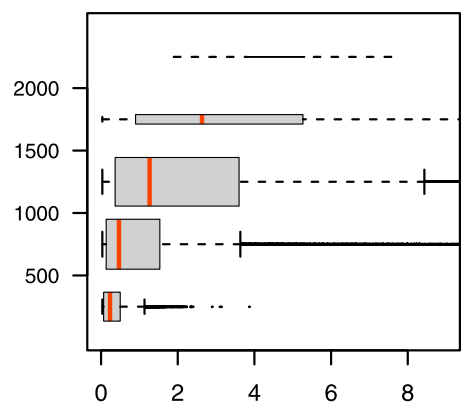

Oct

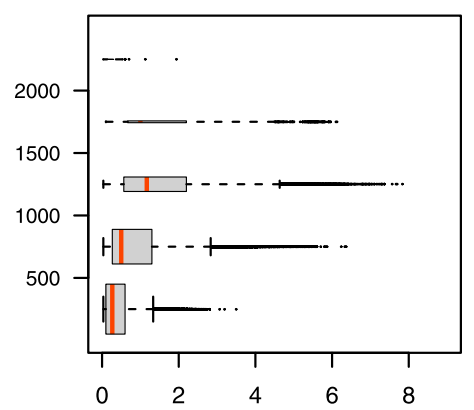

Feb

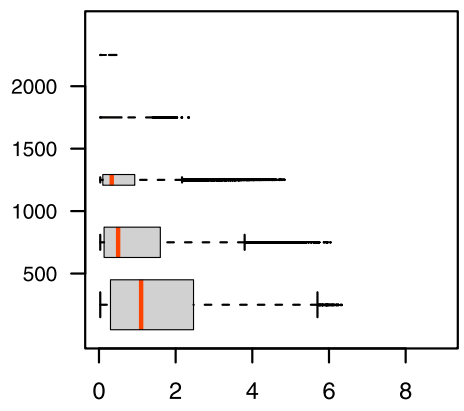

May

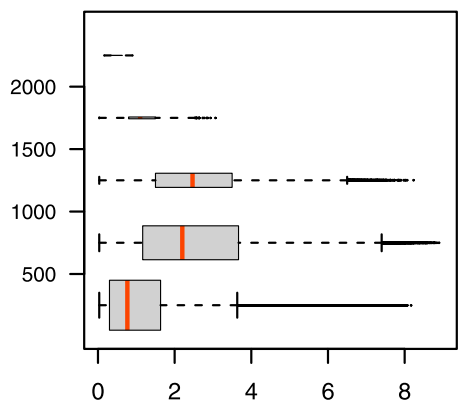

Aug

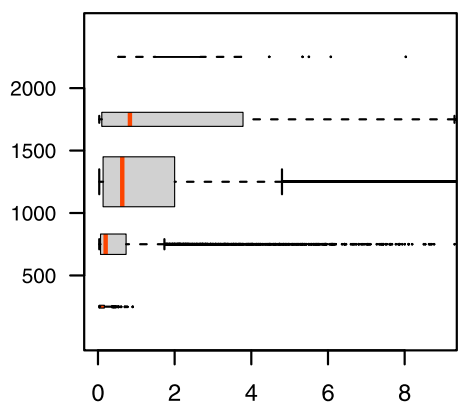

Nov

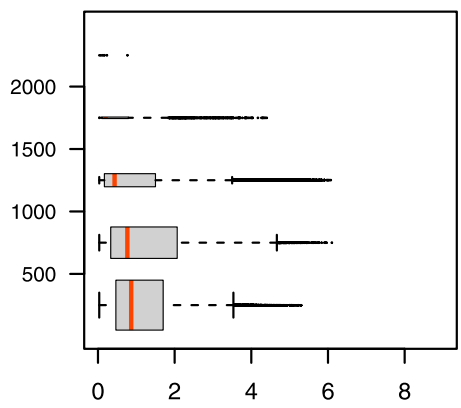

FIG. 3. As in Fig. 2, but as boxplots of ROS counts aggregated over the whole mainland and grouped according to five elevation bands $(<500,500 \leq 1000,1000 \leq 1500,1500 \leq 2000$, and $>2000 \mathrm{~m})$. Boxplot widths are weighted by the amount of land area with nonzero ROS counts, for each month. 

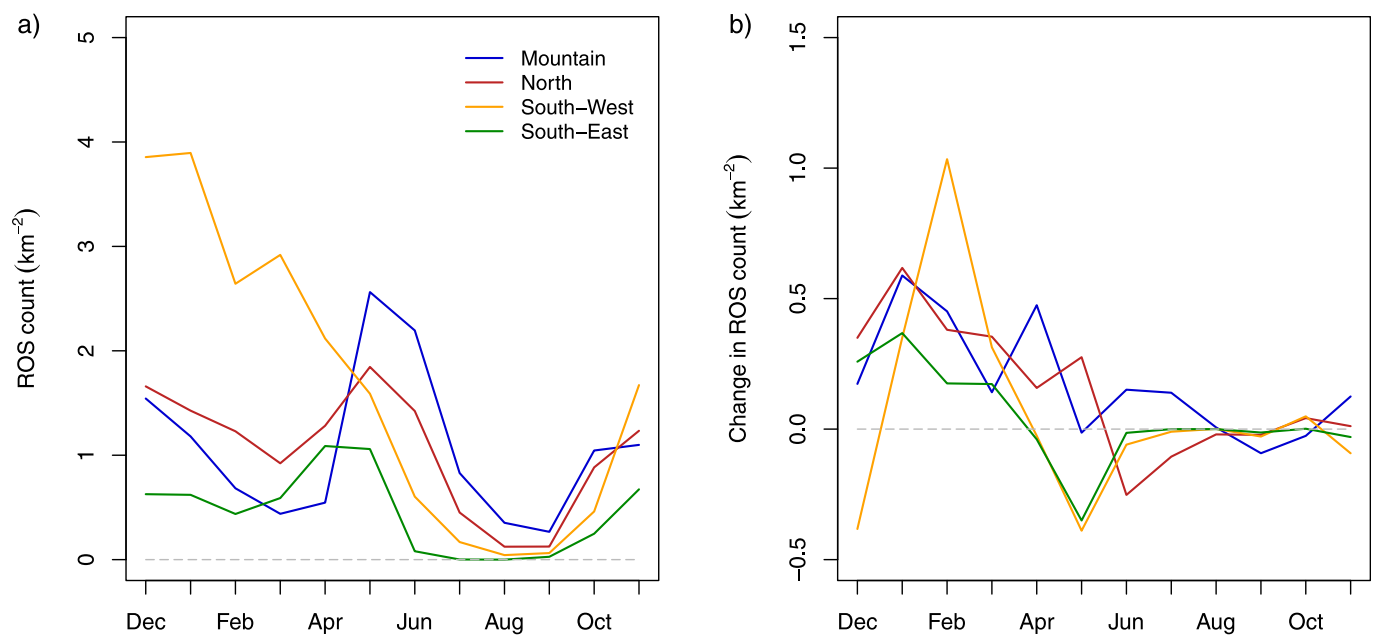

FIG. 4. (a) Average monthly counts of daily ROS events for the period 1961-90, and (b) change in average monthly counts of daily ROS events between 1961-90 and 1981-2010, for area averages over each macroregion (average over all 1-km grid squares).

dominate in the Southwest region in winter, reflecting the patterns seen in Fig. 2 (particularly for January and February). However, despite an exhibiting increasing trend, it is not statistically significant due to the large variability in counts. This likely reflects the large interannual variability of rain in western Norway (see section $2 \mathrm{c}$ ). It also reflects the fact that these regionally averaged values include large areas of ROS decreases toward the coasts, which can to some extent cancel out the areas of more intense increases in the higher-elevation foothills. Conversely, the increasing trend in the Mountain region is statistically significant for winter and spring, reflecting a more spatially coherent pattern, and likely also a lower annual variability; likewise for the spring increase and summer decrease in the North region. Figure 7 also illustrates the contrast in ROS activity within and outside of the snow season.

\section{c. ROS correlation with large-scale atmospheric circulation}

The correlations of our ROS events against the NAOi, AOi, and SCAi are performed for the most active ROS seasons of winter and spring, as identified in Fig. 7, and over the entire data period (daily ROS counts are first summed for each season). Figure 8 shows maps of the correlations.

With respect to the NAOi, strong areas of positive correlation are found in winter in the Southwest region and western flank of the Mountain region (Fig. 8a), with other notable regions along the high-elevation spine of the North region and some areas of the Southeast region. This geographical pattern also corresponds well to the signature of winter ROS events in our baseline climatology (Fig. 2). For spring (Fig. 8b) we see a similar, but rather diminished, pattern-likely reflecting the fact that less ROS events occur in this season for the Southwest region (Fig. 2). However, there is an appreciable increase in areas of correlation for the far north, perhaps reflecting snow-on-snow events now becoming ROS events in these warmer months (particularly May).

With respect to the AOi, we see similar correlation characteristics (Figs. 8c,d) as for the NAOi, which is not surprising given the affinity between the two indices (Thompson and Wallace 1998; Hurrell et al. 2003). However, correlations are now generally somewhat stronger and more widespread, suggesting a slightly more dominant role of this circulation.

With respect to the SCAi, areas of negative correlation are found in winter (Fig. 8e) with a similar pattern to the NAOi and AOi correlations- - but not as strong, not as far north as for the AOi, and not for the Southeast region. Likewise for spring (Fig. 8f), there is a correlation pattern similar to those for the other two indices, but with notable correlations in Finnmark county in the far northeast.

To better understand the nature of the correlations, Figs. 9 and 10 show scatterplots of circulation index versus ROS count for winter and spring, respectively, with each data point labeled with the year to which the data belong. These plots also point to stronger correlations in winter than in spring. They also show the AOi is the circulation index showing the strongest linearlike relationship with ROS count, particularly in the Mountain and North regions. However, such linearity is not apparent for many of the other scatterplots, suggesting more complex relationships (e.g., for the 
Dec

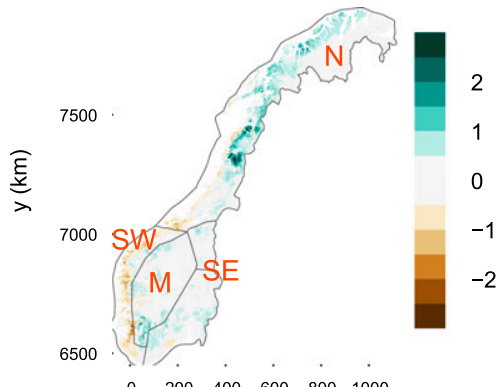

$\mathrm{x}(\mathrm{km})$

Mar

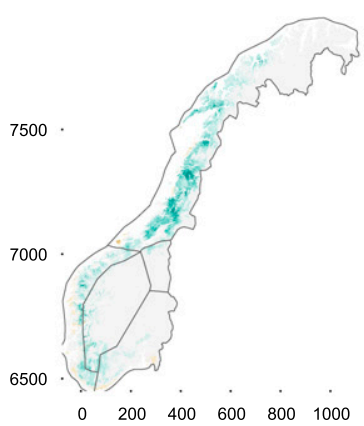

Jun

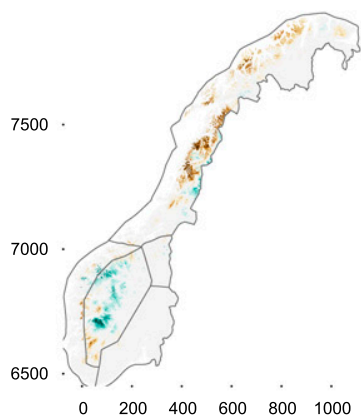

Sep

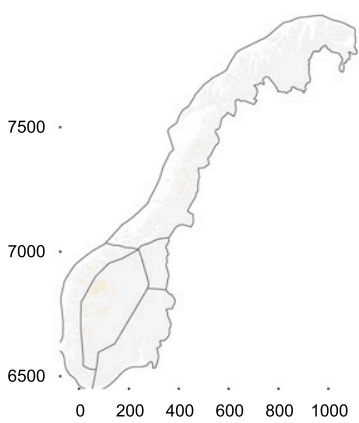

Jan

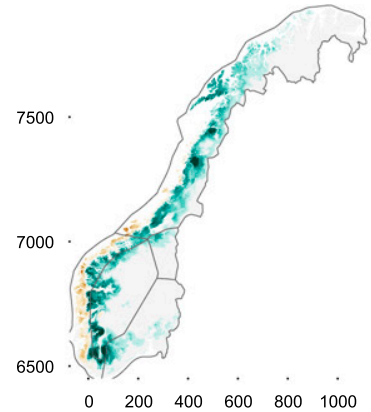

Apr

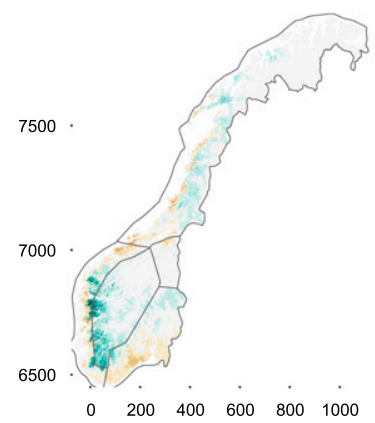

Jul

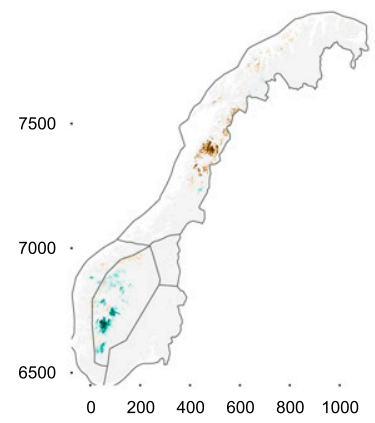

Oct

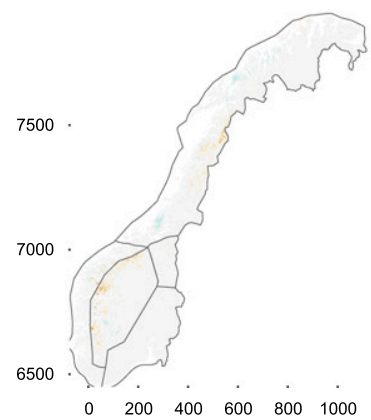

Feb

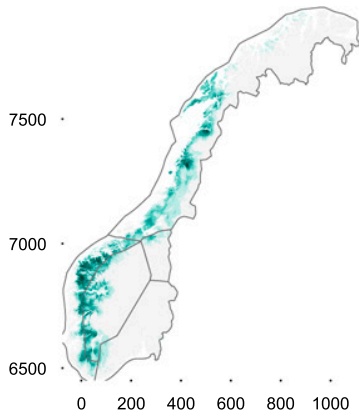

May

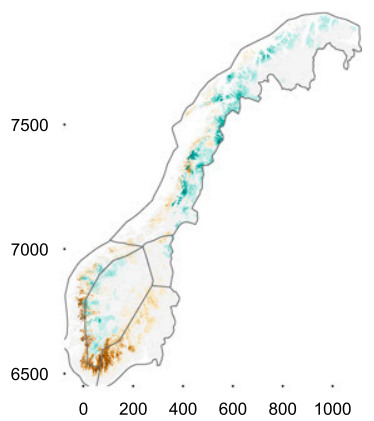

Aug

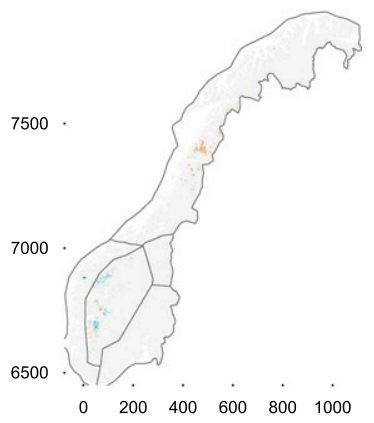

Nov

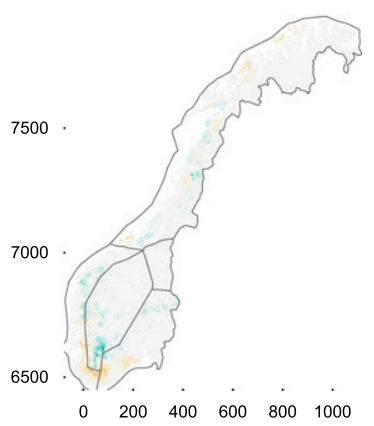

FIG. 5. As in Fig. 2, but now for the change in counts between 1961-90 and 1981-2010. 

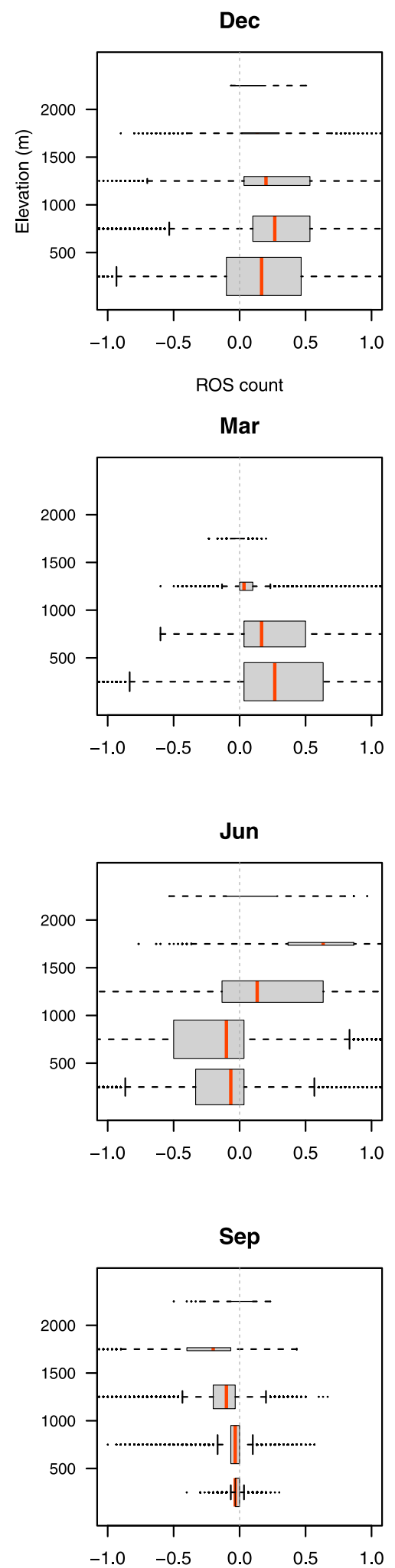
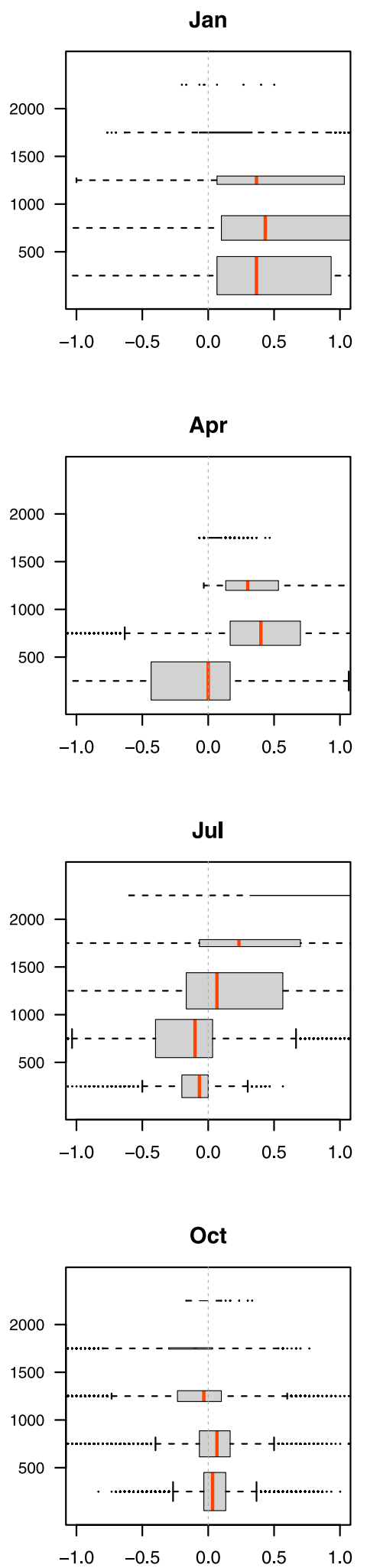
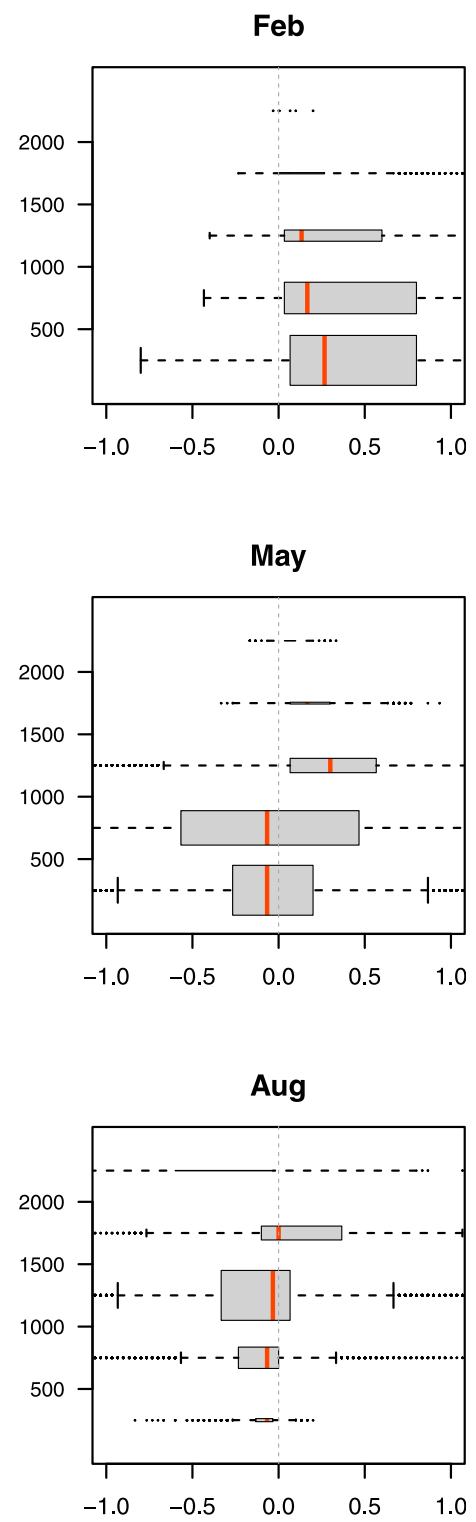

Aug

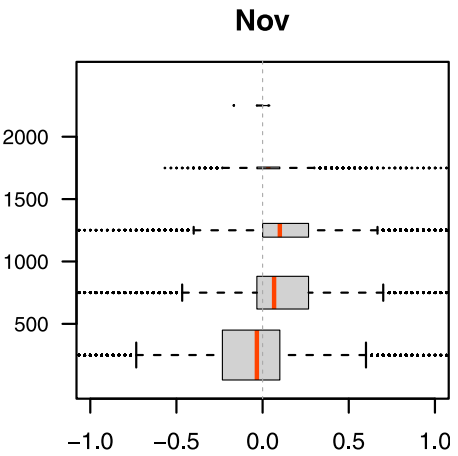

Fig. 6. As in Fig. 3, but now for the change in counts between 1961-90 and 1981-2010. 


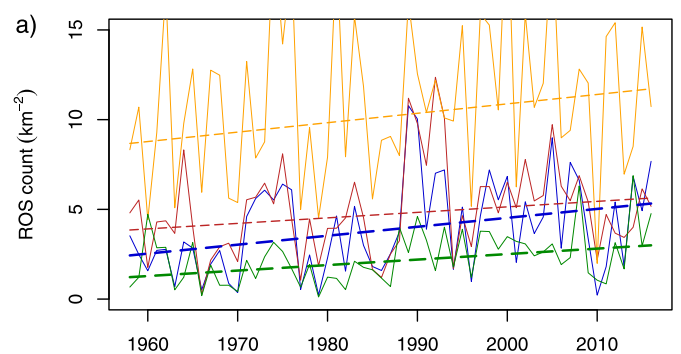

b)
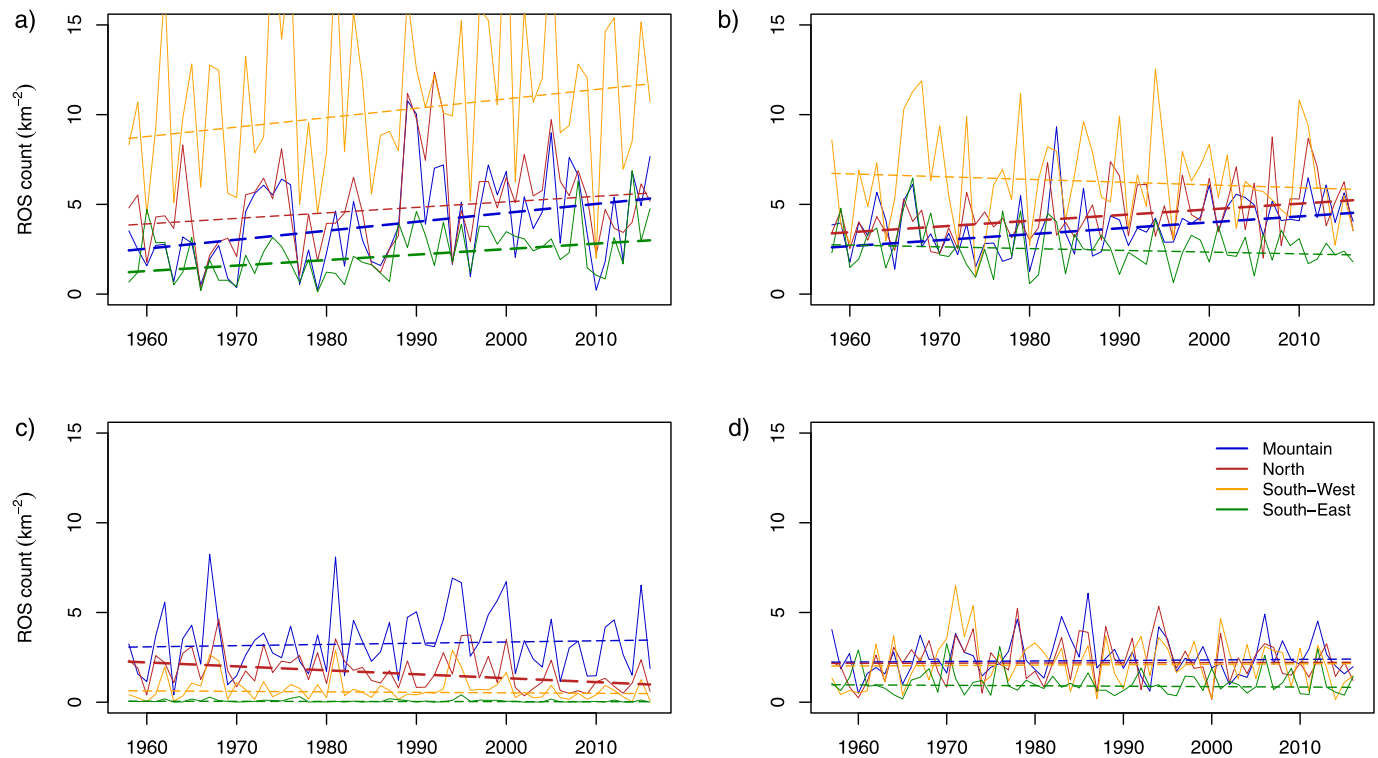

FIG. 7. Seasonal time series (from September 1957 to November 2016) of ROS counts, averaged over each macroregion (average over all 1-km grid squares within a region), for (a) winter (December-February), (b) spring (March-May), (c) summer (June-August), and (d) fall (September-October). Dashed lines show fitted trends, with thicker lines distinguishing significant (5\% level) trends.

Southeast region). Individual years, or clusters of years, with extreme ROS counts generally correspond to periods with extreme values of a circulation index. For example, the years around 1990 are prominent in the scatterplots, particularly for the winter AOi (Fig. 9, second row), and this matches a large positive change in the index during this period (e.g., see chart here: www.cpc.ncep.noaa.gov/products/precip/CWlink/daily_ ao_index/month_ao_index.shtml).

To investigate longer-term relationships, beyond periods of a few extreme years, we correlate the longterm (1957-2016) time series of circulation indices with ROS counts, by macroregion. This shows which index is the most influential on ROS count for a macroregion, following the method of Irannezhad et al. (2017). The correlation coefficients for winter and spring are presented in Tables 1 and 2, respectively. They confirm that the AOi has the strongest relationship with winter ROS count for all macroregions, except the Southeast where the NAOi is slightly more influential. For spring, the picture is more mixed, with the AOi most influential in the Mountain region, the SCAi most influential in the North and Southwest regions, and the NAOi most influential in the Southeast (however, there is generally little difference between the correlation coefficients for a given region, and nor are they always significant).

To visualize the most important long-term relationships and trends, we plot the time series of winter and spring ROS counts, along with their most influential circulation index. This is done only for macroregions where a significant ROS trend has already been found (see Fig. 7). Figure 11 shows these plots and particularly illustrates the AOi influence on Mountain region winter ROS counts, with both variables showing significant positive trends $(+0.50$ daily ROS counts per kilometer squared per decade, and +0.12 AOi per decade; Fig. 11a). A similar statement can be made for spring, albeit with a nonsignificant AOi trend $(+0.33$ daily ROS counts per kilometer squared per decade, and +0.07 AOi per decade; Fig. 11c). The NAOi is most influential only on Southeast region winter ROS counts $(+0.31$ daily ROS counts per kilometer squared per decade, and +0.25 NAOi per decade; Fig. 11b). Likewise, the SCAi is most influential only on North region spring ROS counts, showing anticorrelated trends $(+0.32$ daily ROS counts per kilometer squared per decade, and -0.14 SCAi per decade; Fig. 11d).

\section{Discussion}

Our results suggest that various hydrometeorological and geographical factors shape ROS climatology, and its change, across the Norwegian mainland. These factors, which range from, for example, local orographically driven rainfall to the large-scale atmospheric circulation, operate and interplay in different ways, depending on the region and season. Here we discuss the most notable features. 


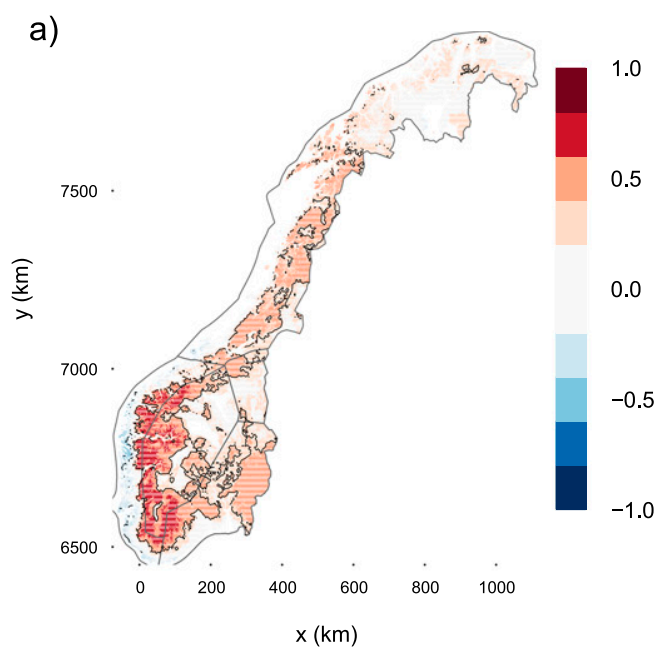

c)

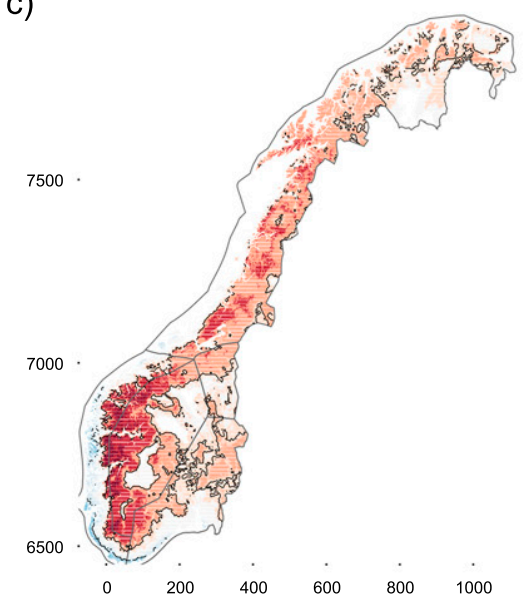

e)

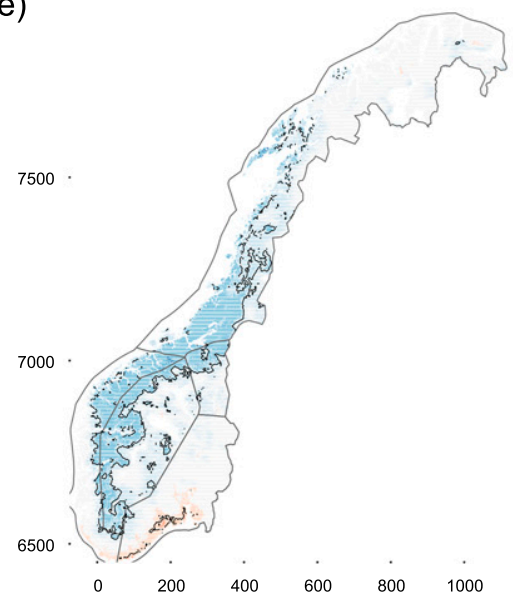

b)

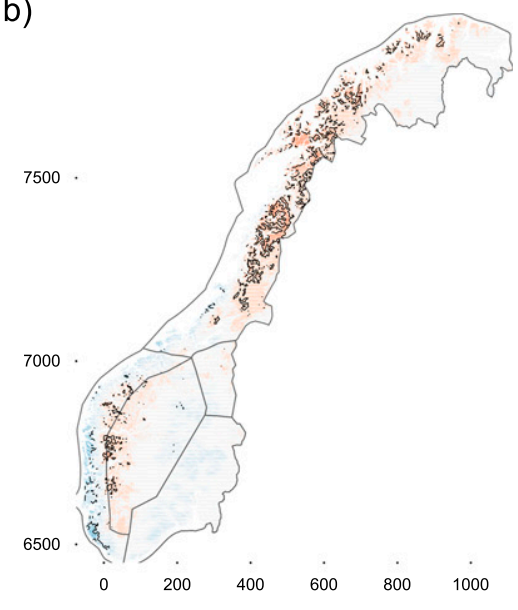

d)

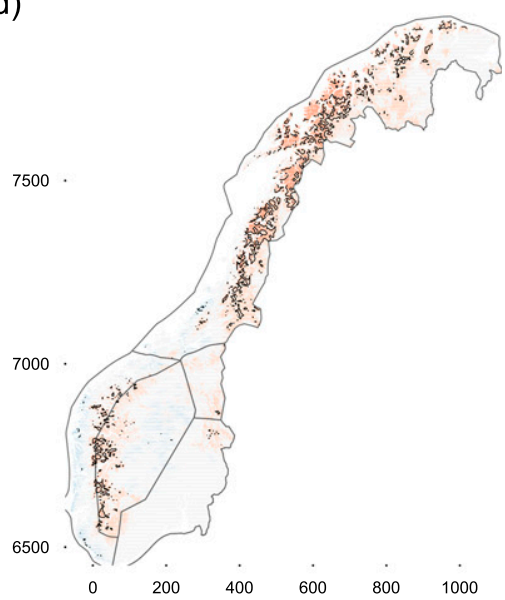

f)

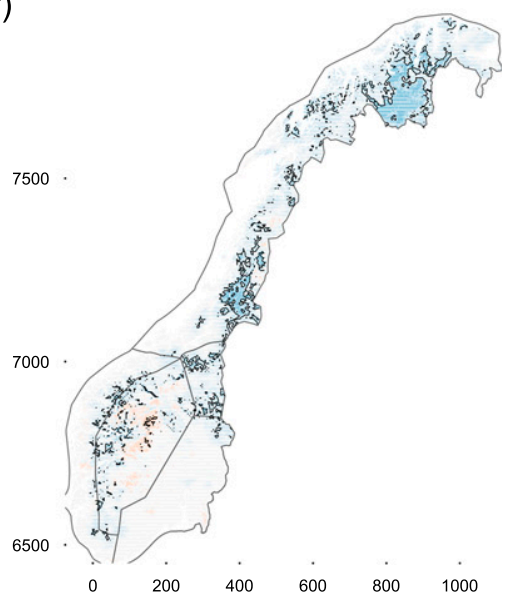

FIG. 8. Correlation (Spearman's coefficient) of ROS count with (a),(b) NAOi; (c),(d) AOi; and (e),(f) SCAi for (left) winter and (right) spring. The data period and the winter and spring seasons are as stated for Fig. 7. Areas of significant (1\% level) correlation are demarcated by black contours. 

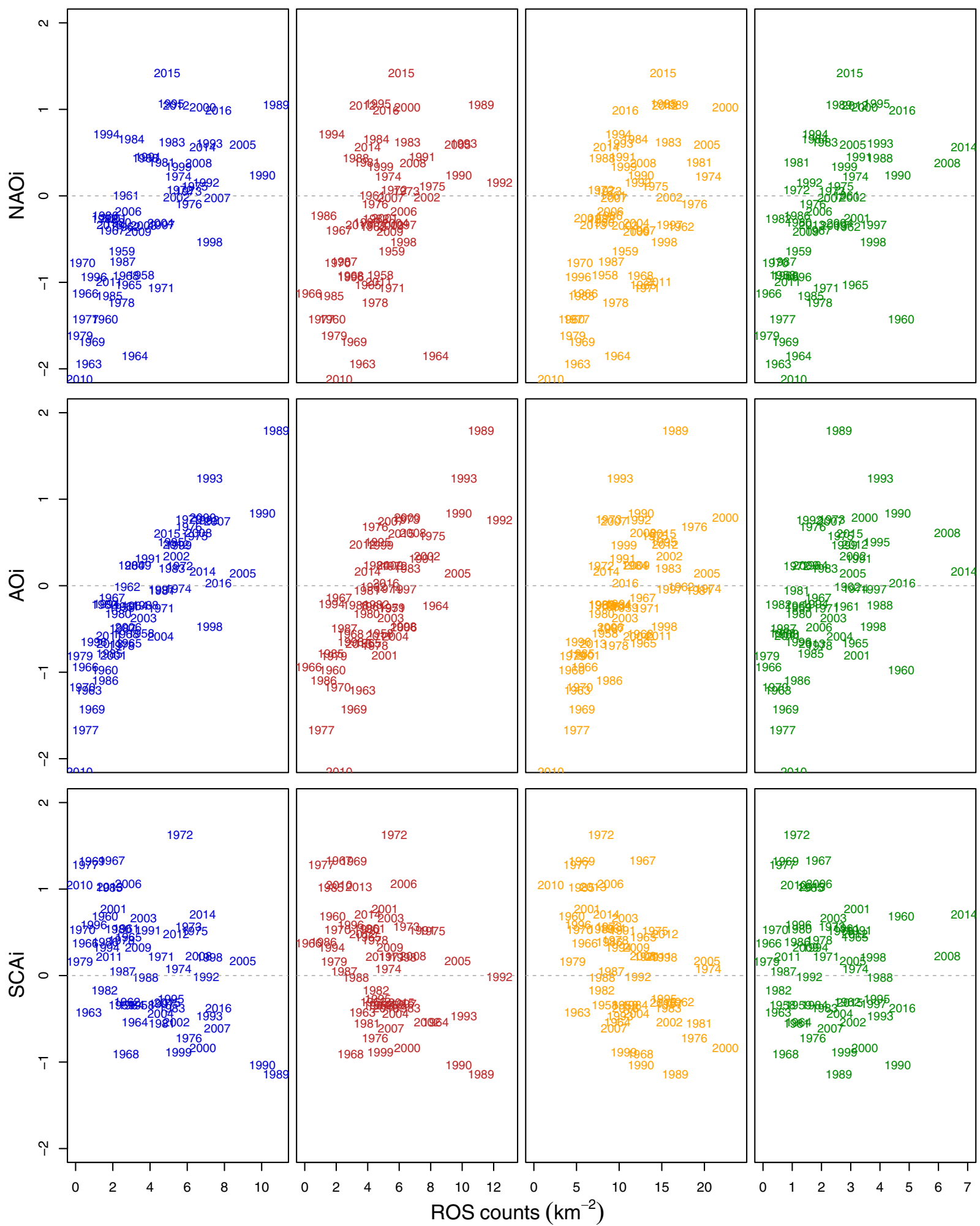

1972

199691967

201ฉอง 6

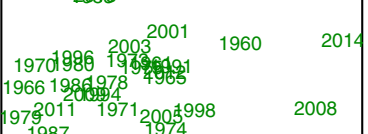

$9720111_{1971} 2005998 \quad 2008$

$1987-1992$ - 1974

1982

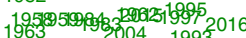

1964204021993

1976

$1968 \quad 1993000 \quad 1990$

\section{ROS counts $\left(\mathrm{km}^{-2}\right)$}

FIG. 9. Scatterplots of circulation index vs ROS count averaged over macroregions for winter for (left) Mountain, (left center) North, (right center) Southwest, and (right) Southeast. Each data point is labeled with its year, and the data period is as stated for Fig. 7. 

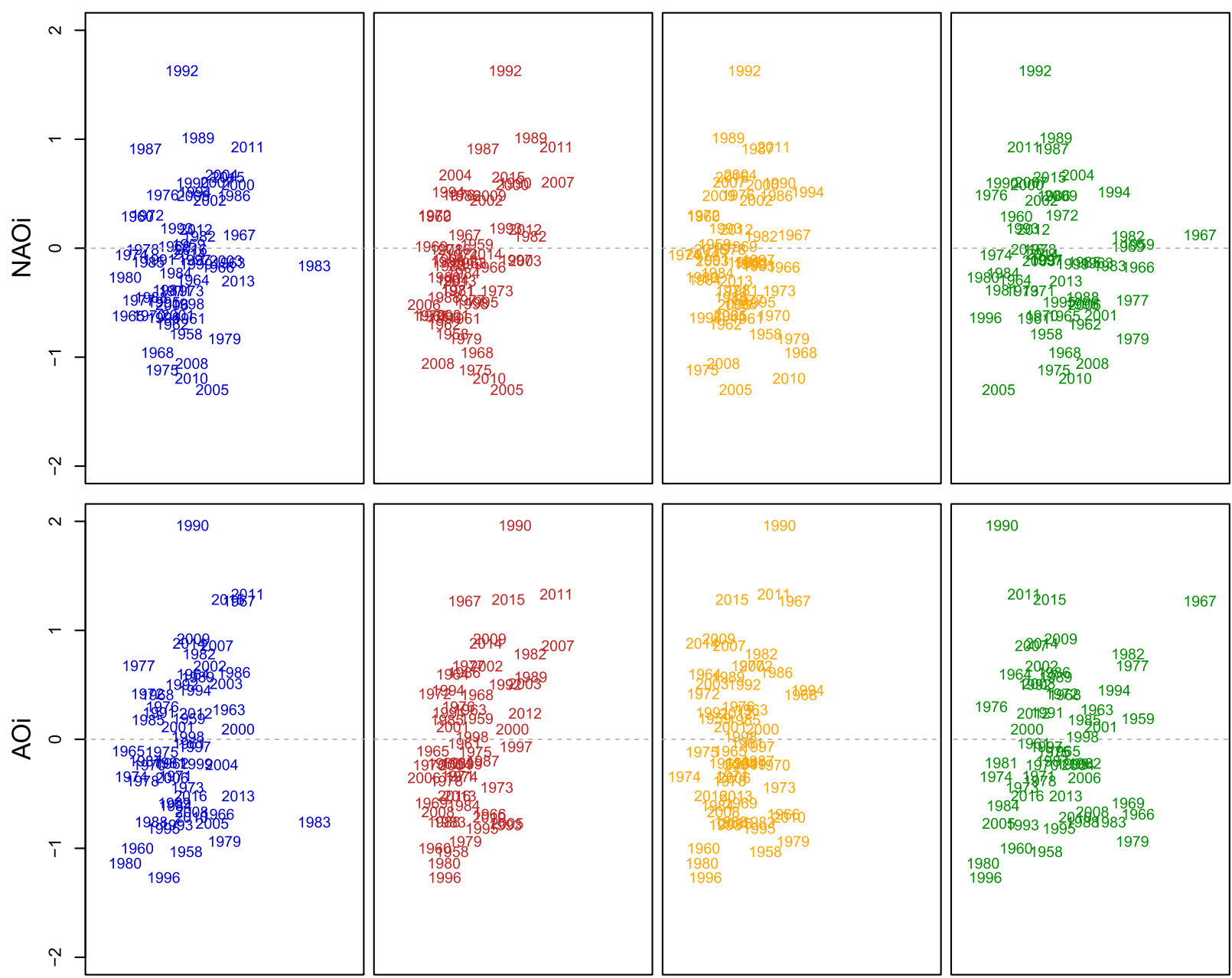

1990
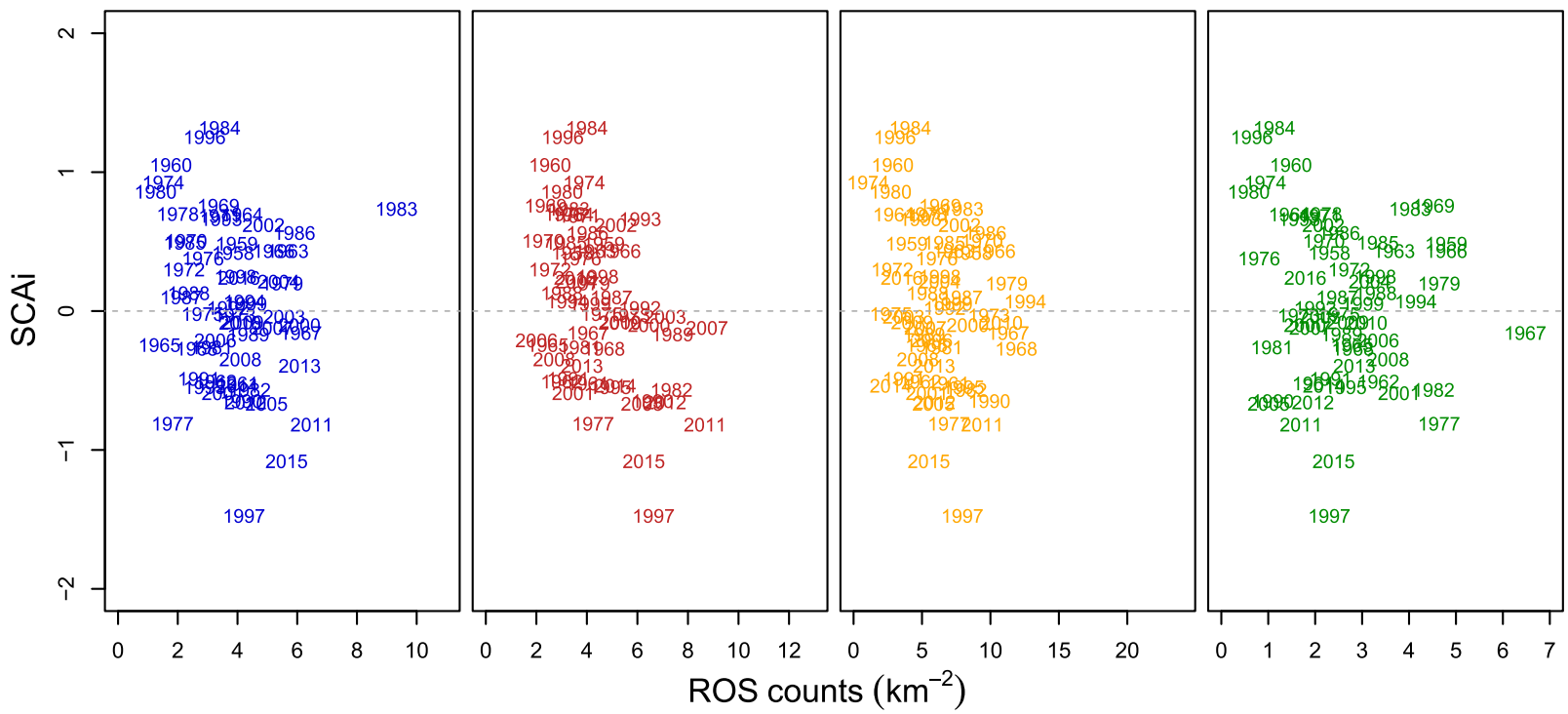

FIG. 10. As in Fig. 9, but for spring. 
TABLE 1. Correlation (Spearman's coefficient, shown to two significant figures) of winter ROS count with circulation index (see text) for the four macroregions shown in Fig. 1, using seasonally averaged data from December 1957 to February 2016. Correlations significant at the $1 \%$ or $5 \%$ level are shown in boldface or italic type, respectively.

\begin{tabular}{lcrcr}
\hline \hline & Mountain & North & Southwest & Southeast \\
\hline NAOi & $\mathbf{0 . 7 0}$ & $\mathbf{0 . 4 7}$ & $\mathbf{0 . 5 3}$ & $\mathbf{0 . 5 8}$ \\
AOi & $\mathbf{0 . 8 4}$ & $\mathbf{0 . 7 0}$ & $\mathbf{0 . 6 4}$ & $\mathbf{0 . 5 3}$ \\
SCAi & $\mathbf{- 0 . 4 7}$ & $\mathbf{- 0 . 4 1}$ & $\mathbf{- 0 . 5 3}$ & -0.13 \\
\hline
\end{tabular}

\section{a. Baseline climatology (1961-90) and relationship with large-scale atmospheric circulation}

It is clear from our baseline climatology (section 3a; Figs. 2, 3, and 4a) that the majority of ROS events occur in winter-spring-especially in high-elevation areas of the Southwest region, extending higher into the western flank of the Mountain region (likewise for highelevation areas of the North region). This behavior is consistent with western Norway's weather being dominated by Atlantic frontal storm systems for most of the year (Dyrrdal et al. 2012; Hanssen-Bauer et al. 2015), bringing rain on winter snow.

The straddling, however, of the winter-spring ROS signal across the Southwest and Mountain regions also suggests that some redefinition of these regions-which were derived from those originally created with mainly rain and elevation in mind (Dyrrdal et al. 2012) - may be beneficial in future ROS studies. For example, the greatest winter-spring ROS activity occurs in the $500 \leq 1000 \mathrm{~m}$ elevation band in the Southwest region (Fig. S6). This reinforces the notion from Fig. 2 that the Southwest region could be merged with the western flank of the Mountain region, which is also very active at high elevations (Fig. S4 in the online supplement). For example, one might chose a macroregion that amalgamates the regions $4,5.1,5.2,6.1,6.2$, 8.1, and 8.2 in Dyrrdal et al. (2012), where these are above $500 \mathrm{~m}$, as this better reflects the strong west-east ROS gradient across southern Norway. However, we felt there was no clear a priori way of determining such exact macroregions without first doing our analysisand the suitability of these regions changes for other time periods (e.g., in May it seems appropriate to keep the current Mountain region definition). This is another reason, in addition to the reasons given in section $2 \mathrm{c}$, for why we proceeded with this study by using the macroregions of R18. In this sense, a consequence of our study is an examination of how suited the R18 choice of macroregions actually are to rain-on-snow events, and the findings of our study may serve as a guide for detailed future studies.
TABLE 2. As in Table 1 but for spring, using seasonally averaged data from March 1958 to May 2016.

\begin{tabular}{lcrcc}
\hline \hline & Mountain & North & Southwest & Southeast \\
\hline NAOi & 0.28 & $\mathbf{0 . 3 7}$ & 0.01 & -0.15 \\
AOi & 0.30 & $\mathbf{0 . 4 4}$ & 0.10 & 0.08 \\
SCAi & -0.25 & $\mathbf{- 0 . 4 5}$ & -0.22 & -0.14 \\
\hline
\end{tabular}

The pattern of western winter-spring ROS activity also correlates well with the large-scale NOAi (Figs. 8a,b), and is perhaps not surprising given the aforementioned dominance of western Norwegian precipitation by Atlantic storminess, which is reflected by this index. This correspondence may also partly account for the large variability in our winter ROS time series (Fig. 7a), given the large year-to-year and decadal variability of the NAOi (Hurrell et al. 2003). Our findings are also consistent with previous studies correlating the NAOi with Norwegian precipitation (Uvo 2003) and wind climate (Iversen and Burningham 2015). In particular, Uvo (2003) found the highest precipitation correlations for meteorological stations clustered along the western Norwegian coast. Complementary to this, Iversen and Burningham (2015) used reanalysis to indicate that a positive NAOi is strongly correlated with increased southwesterly winds over Norway up to about $68^{\circ} \mathrm{N}$, which would explain why our ROS correlations diminish rapidly above this latitude.

We see similar correlation characteristics with respect to the AOi, but generally slightly stronger and more widespread (Figs. 8c,d), and more linear in nature (Figs. 9 and 10). This is presumably because the associated circulation, which has a center of action over the Arctic that extends into Norway, brings a mixture of colder temperatures and precipitation that is more conducive to ROS events. In particular, significant correlations for winter and spring now reach into the furthest northern county of Finnmark, where Atlantic weather has less influence. The analysis of Cohen et al. (2015) also indicates that winter AOi has a more widespread correlation with northern European ROS events than the NAOi (for the period 1979-2013). They also find high correlations on the western Norwegian coast, and into the north-albeit the coarse resolution of the reanalysis that they use hampers more detailed conclusions (and their ROS definition is also a little different).

For the SCAi, Bueh and Nakamura (2007) and Liu et al. (2014), using reanalysis, indicate that a positive SCAi is associated with dry conditions over much of western Norway for winter. This supports our findings of an anticorrelated ROS with the SCAi, for this area (Fig. 8e). In spring, the anticorrelations are generally 
a)
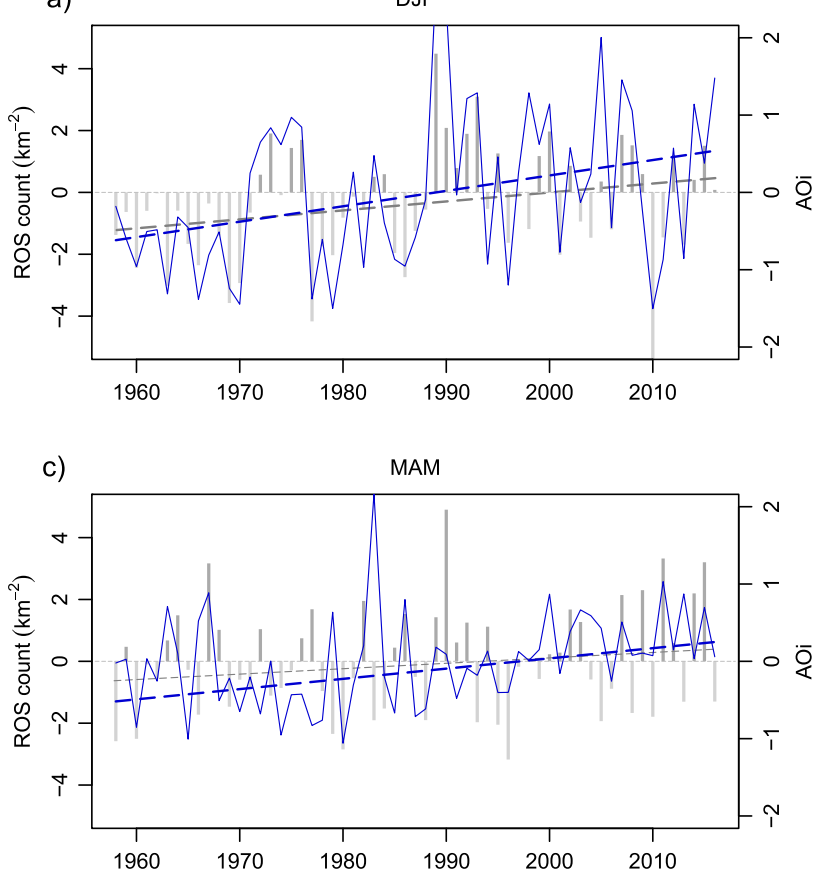

b)

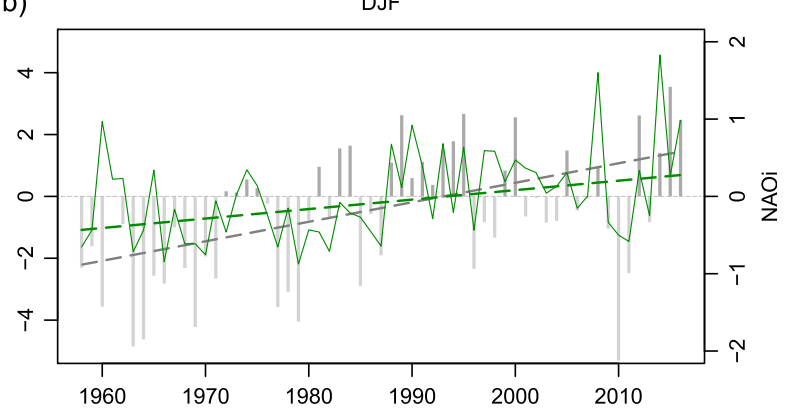

d)

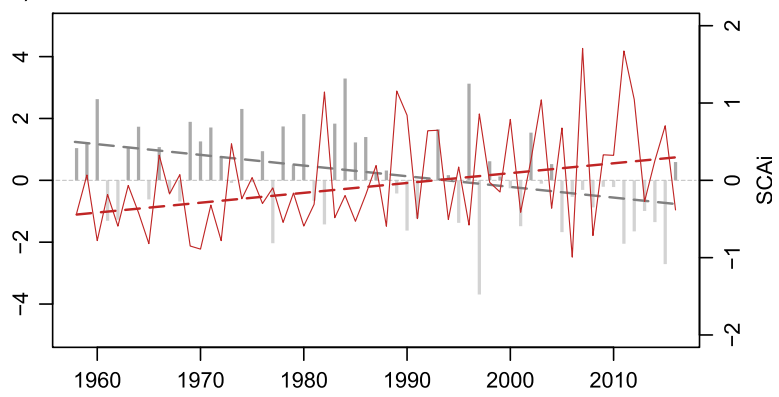

FIG. 11. Time series of ROS count averaged over a macroregion (lines; left axis) and most influential circulation index (bars; right axis) for the (a) Mountain region in winter, (b) Southeast region in winter, (c) Mountain region in spring, and (d) North region in spring. All values are anomalies relative to the data period stated for Fig. 7. Dashed lines show fitted trends, with thicker lines distinguishing significant $(5 \%$ level) trends.

restricted to the Mountain, North, and parts of the Southeast region (Fig. 8f). This is because this is where ROS events now dominate (Fig. 4a). However, the spring anticorrelations for the North are significant and higher than in winter (Tables 1 and 2). This may be because the centers of action of the Scandinavia circulation pattern become better defined in this season (despite also becoming smaller) (Bueh and Nakamura 2007). It would also help to explain why in spring the significant long-term positive trend in North region ROS (Fig. 7b) appears to be most influenced by a significant negative trend in the SCAi (Fig. 11d, Table 2).

Accompanying the dominant western and northern ROS activity described thus far, a rain shadow-type pattern is apparent in the drier Southeast region, on the leeward side of the Mountain region. This Southeast region experiences a colder, more continental, climate (see section 2c). Thus more southerly, and to a lesser extent easterly, moist continental flows are probably responsible for most of the ROS activity here. This occurs mainly later in the spring, particularly in April/ May, as illustrated by the peak in Fig. 4a, which is still relatively weak compared to the other regions. Indeed, the NAOi and AOi usually diminish in spring, as reflected in the lower correlations in Figs. $8 \mathrm{~b}$ and $8 \mathrm{~d}$, and Uvo (2003) also found much lower NAOi-precipitation correlations on the leeward side of the Scandinavian mountain chain, suggesting a sheltering of these regions from Atlantic winds (and any rain here perhaps more influenced continental moisture sources; from the Baltic Sea in some cases).

Furthermore, the decrease of ROS activity in the Southwest and Southeast region toward the end of spring and into summer is consistent with the winter snowpack gradually declining as local temperatures warm, and additional warm winds bringing fluxes of latent and sensible heat that can leave snow susceptible to melt (e.g., Marks et al. 1998; Corripio and LópezMoreno 2017). Also, preceding ROS events in the season that do not immediately generate snowmelt can instead add to the heat and liquid water content of the snowpack, leaving it ripe for melt and runoff upon subsequent ROS events (e.g., Singh et al. 1997; Kroczynski 2004).

Another notable ROS signal in our baseline climatology is in late spring-early summer (May-July), where events dominate the Mountain region and high-elevation areas of the North region. This is consistent with the snow cover persisting longer in these areas, and with a tendency for snow-on-snow events to become rain-onsnow events in the warmer months [including convective rain particularly toward the south, in addition to 
westerly moist flows (Dyrrdal et al. 2018)]. This elevationdependent behavior for warmer months reflects that in other ROS-affected parts of the world (e.g., McCabe et al. 2007; Pradhanang et al. 2013; Morán-Tejeda et al. 2016; Jeong and Sushama 2018), and in some cases individual summer ROS events can be distinct from winter ones (Pomeroy et al. 2016). However, one factor to bear in mind is the quality of the dataset at high elevations, where the underlying station network is relatively sparse. For example, the model for vertical precipitation gradient applied in the dataset may be overestimating high-elevation values in some southern areas; furthermore, we may in part be seeing a higher rain signal in warmer months because undercatch is less of an issue than for lighter-weight mixed rain/snowfall in colder months (Dyrrdal et al. 2012). This issue of highelevation data quality also applies to the underlying temperature data that determine whether precipitation is treated as rain or snowfall and dictate when snowmelt occurs on the ground (see section 2a).

In terms of ROS impacts, there are some cases where, for example, floods occurred (Roald 2013) during individual seasons where we find extreme values of the circulation indices and ROS count. For example, we find spring 1967 is an extreme ROS season in the Southeast region (Fig. 10, fourth column) and the AOi is particularly high. A large snowmelt flood occurred in May 1967 across southeastern Norway. Similarly, for winter 1990, we find extreme SCAi and ROS values for the North region (Fig. 9, second column). Floods occurred within this region in December 1989 in Lakselv, and near Salten. Other less prominent cases can also be made for the NAOi (e.g., November 2005 floods in and around Hordaland county, western Norway; cf. Fig. 9, third column). However, some large ROS floods, such as observed in May 2013 in Oppland county (mainly in the Mountain region), are instead associated with a so-called $\mathrm{Vb}$ atmospheric circulation (according to a German weather classification system; Messmer et al. 2015). This circulation is characterized by warm moist air originating from the central Atlantic through to the western Mediterranean, which then turns north around the eastern Alps. Occasionally, it can continue toward southern Norway, where it collides with cold westerly flows resulting in very heavy frontal precipitation (Roald 2015; Devoli et al. 2018). This is probably why the corresponding year does not show up as extreme for the circulation indices in our analysis, even though the ROS count does (Fig. 10, first column). Such Vb events, although relatively rare for Norway, are nevertheless historically the cause of the most devastating floods.

Furthermore, many of the years in Figs. 9 and 10 are not extreme, yet ROS floods are known to have occurred occurring during those times (Roald 2013). This discrepancy is probably because our analysis only considers seasonally and regionally averaged data points, to give a macroview of ROS characteristics across mainland Norway (see section 2a). ROS floods typically occur over smaller spatiotemporal scales and are better characterized by translating the meteorological ROS signal into runoff, via the use of hydrological modeling (e.g., Pradhanang et al. 2013; Surfleet and Tullos 2013; Rössler et al. 2014; Wayand et al. 2015; Corripio and López-Moreno 2017). Likewise, some years in Figs. 9 and 10 are extreme but no ROS floods are known to have occurred at those times. This again points to the need for better understanding via hydrological modeling. In particular, the rain versus snowmelt contribution to runoff can be important in dictating the flood generation processes in different parts of Norway (Vormoor et al. 2016). All this highlights the need for detailed end-to-end analysis when considering the causes of individual ROS events and their impacts: from the large-scale circulation to the local hydrology.

\section{b. Change relative to baseline climatology (1981-2010 vs 1961-90)}

Similar to the pattern of ROS activity for the baseline climatology, the change in ROS activity is dominated by a winter-spring signal (section 3b; Figs. 5, 6, and 4b), especially in the Southwest region-with a mixed signal of coastal decreases, and higher-elevation increases continuing into the western flank of the Mountain region (likewise for high-elevation areas of the North region). Again the increases straddle the Southwest and Mountain regions-reinforcing the notion that a redefinition of these regions could be considered with respect to ROS.

These ROS decreases in coastal areas are consistent with less snow cover in a warming climate. Indeed, R18 show that temperature has increased in all regions throughout winter-spring-particularly the Southwest region-and that this is significantly correlated with snow-cover decrease (see their Figs. 5 and 6). Conversely, the ROS increases in high-elevation areas are consistent with a persistence of snow cover in these cooler areas (where temperature stays below the freezing temperature despite a warmer climate), along with more precipitation in a warmer climate with increased atmospheric moisture-holding capacity (Trenberth 1999). This also agrees with our finding that the significant long-term ROS increases in the Mountain region (Figs. 7a,b) appear to be most influenced by positive trends in the AOi (Figs. 11a,c; Tables 1 and 2), which would bring more precipitation to this region. 
However, the nature of these ROS increases depends to some extent on whether any increased precipitation is in the form of more rain or more snow. If the latter, as expected in the highest elevation foothills and into the Mountain region, then this could instead potentially provide a base for increased ROS events in the later spring months. For example, R18 show that, despite warmer temperatures, snow cover changes little from January-March in the Mountain region, but precipitation increases - which is consistent with our finding of increased ROS. However, they also find SWE increases somewhat for the region, suggesting that increased snowfall rather than rain is occurring at the highest elevations farther up from the foothills of the western flank-and that this snow then forms a base for increased ROS activity when rain falls in warmer months (particularly April; Fig. 4b). This overall winterspring behavior in ROS activity is also in line with the findings of Dyrrdal et al. (2012), and Dyrrdal et al. (2013), whereby snow depth decreases are dominated by higher temperature in the warmer (coastal) Norwegian climates, and snow depth increases are dominated by higher precipitation in cooler (mountain) climates, for recent decades.

In late spring, and notably in May, the decreases in the Southeast region may be for similar reasons as for the winter-spring decrease in the Southwest region (see Fig. 4b). Specifically, the Southeast decreases are also in coastal and low-elevation areas, and for this region precipitation changes very little relative to the baseline, whereas temperature increases in all preceding months and is highly correlated with decreases in SWE and snow cover (R18, their Figs. 5 and 6), suggesting temperature is the driver of the ROS decline. In particular, R18 found statistically significant warming in April (their Fig. 1) with accompanying decreases in snow cover, and suggested that a positive snow-albedo feedback plays a role in earlier snowmelt and shortening of the snow season, which would account for our ROS declines in May.

A similar argument could be made for the summer (particularly June) ROS declines in the North region, where again R18 found widespread warming across this region, and decreases in snow cover in similar locations to our ROS declines. Furthermore, in this North region case, the collocated ROS increases in preceding months may also have contributed to less snowpack remaining for any ROS activity to occur in summer. Additionally, those ROS increases may themselves be due to climatic warming resulting in rain rather than snowfall-that is, an earlier start of the snow free period. Indeed, R18 (their Fig. 5) show that North region snow cover and SWE decrease for months preceding June while temperature and precipitation generally increase, implying increased rain.

Also in summer, small areas of ROS increase are present in the highest-elevation areas of the Mountain region, suggesting locations where snow has persisted, only to be affected by increased summer rain-akin to the aforementioned pattern for higher-elevation areas in winter-spring in the Southwest region.

\section{Conclusions}

ROS events are multivariate hydrometeorological phenomena, with complex processes occurring on and within the snowpack, and a range of impacts. The quantification of ROS events, and detection of any changes, can be difficult because events generally occur at high latitudes and/or in mountainous areas, which typically have sparse observation networks (and instruments may not always distinguish directly between rain and snowfall, with air temperature instead employed to estimate the separation). Likewise, reanalysis products are typically too coarse to resolve what are often very localized events, particularly when topographic gradients in temperature, rain, and snow, are important.

In this study we have taken advantage of the highresolution $(1 \mathrm{~km})$ seNorge hydrometeorological dataset for mainland Norway, capable of resolving rugged topography and complex drainage networks. Even so, the effective resolution of information in the dataset may be less than $1 \mathrm{~km}$, given that it is derived from meteorological stations that are generally spaced far more than $1 \mathrm{~km}$ apart, especially at high elevations (Dyrrdal et al. 2012). Thus, we have focused on aggregate characteristics over larger regions. Specifically, we followed previous studies (Dyrrdal et al. 2012; R18) and grouped our analysis by four macroregions that reflect the diverse range of Norwegian climates: a south central alpine Mountain region, a predominantly Arctic North region, a maritime Southwest region, and a somewhat more continental Southeast region. We also use the findings of R18 for these regions regarding temperature, precipitation, and snow, to underpin our conclusions regarding ROS.

We formulated an ROS definition for daily events based on the literature, and applied it to the seNorge dataset to construct a baseline (1961-90) climatology, as well as examine changes relative to a 1981-2010 climatology. We also examined correlations of our ROS events with the NAOi, AOi, and SCAi to provide a larger-scale context for our findings. The main conclusions are given below and showcase the complexity of these events (as explored further in the discussion). 
For the baseline climatology:

- Winter-spring ROS events in the Southwest region (and to a lesser extent in western areas of the North region) dominate the climatology, particularly in winter and in higher-elevation foothill areas. Some continuation of this signal occurs into the western flank of the Mountain region-suggesting a redefinition of the macroregions may be appropriate with respect to ROS in future studies, to better reflect the strong west-east ROS gradient across southern Norway. However, this redefinition may not be appropriate for all months (particularly May).

- The winter-spring ROS activity is consistent with western Norway's weather being dominated by Atlantic frontal storm systems, bringing rain on winter snow. Moreover, it correlates well with the NOAi, which also may partly account for the large year-toyear variability we find in ROS activity, particularly in the Southwest region.

- Stronger, more linear, and more widespread winter correlations are found with the AOi, particularly toward the northernmost parts of the mainland. This is presumably because the associated circulation brings Arctic weather that is more conducive to ROS events. In spring, however, ROS is slightly more correlated (negatively) in the North region with the SCAi, and more influenced by a significant negative long-term trend in this index. This may be because the centers of action of the Scandinavia circulation pattern become better defined in this season.

- The dominant winter-spring western ROS activity is accompanied by a less active rain-shadow-type pattern in the Southeast region, leeward of the central Mountain region. Only a relatively small peak in activity occurs in late spring, consistent with weak NAOi and AOi correlations and instead an influence of a more continental climate.

- The ROS activity becomes less frequent in the Southwest and Southeast in late spring into early summer. This is consistent with local warming, and probably warmer winds bringing fluxes of latent and sensible heat, as well as ROS events in preceding months melting the snow, or possibly leaving it ripe for melt upon subsequent ROS events.

- In early spring-late summer, ROS events dominate the Mountain region and high-elevation areas of the North region. This is consistent with the persistence of snow cover in these high areas, and with a tendency for snow-on-snow events to become rain-on-snow events in the warmer months. However, data quality at high elevations with steep topographic gradients is always a factor to bear in mind.
For changes to baseline:

- ROS changes are dominant in winter-spring and the Southwest region. Here there is a mixed signal of coastal decreases consistent with less snow cover in a warming climate, and foothill area increases (also continuing into the western flank of the Mountain region) consistent with more precipitation in a warming climate. The latter also agrees with significant long-term positive trends in Mountain region ROS, which appear to be influenced by long-term positive trends in the AOi.

- The increased winter-spring precipitation may be snowfall rather than rain at higher elevations, potentially forming a base for the increased ROS activity seen later in spring in the Mountain region, in combination with snow-on-snow events transitioning to rain-on-snow events in the warmer months of the year.

- Notable declines in ROS activity occur in spring in the Southeast (and to a lesser extent Southwest) region-predominantly temperature driven (i.e., earlier snowmelt).

- Likewise, summer ROS activity declines in the North region-albeit in this case probably additionally influenced by increased ROS activity for antecedent months. This antecedent activity is itself probably influenced by climatic warming that implies rain rather than snowfall-that is, an earlier start of the snow free period, resulting in less snow remaining in the summer.

We feel that our first attempt at a high-resolution nationwide ROS climatology provides a useful overview that has not thus far been gained from conventional resolution reanalysis- or climate-model-based studies. We have focused on aggregate ROS characteristics of the high-resolution dataset, across different Norwegian macroclimates and seasons. A more detailed end-to-end analysis would be required to understand the nature of individual ROS events and their impacts. It would require consideration of the specific large-scale meteorological conditions, the fidelity of the dataset at small scales, and some form of hydrological modeling. In this sense, we feel our analysis could serve a base for more detailed studies that focus on locations where ROS events have the largest impacts.

Acknowledgments. This work forms a contribution to LATICE (https://www.mn.uio.no/latice), which is a Strategic Research Initiative funded by the Faculty of Mathematics and Natural Sciences at the University of Oslo. We thank Jonathan Rizzi, now at the Norwegian Institute of Bioeconomy Research, for directing us to the seNorge data and for technical advice of various 
kinds and Frans-Jan Parmentier at the University of Oslo for helpful discussions.

\section{REFERENCES}

Beniston, M., and M. Stoffel, 2016: Rain-on-snow events, floods and climate change in the Alps: Events may increase with warming up to $4^{\circ} \mathrm{C}$ and decrease thereafter. Sci. Total Environ., 571, 228-236, https://doi.org/10.1016/j.scitotenv.2016.07.146.

Bueh, C., and H. Nakamura, 2007: Scandinavia pattern and its climatic impact. Quart. J. Roy. Meteor. Soc., 133, 2117-2131, https://doi.org/10.1002/qj.173.

Cohen, J., H. Ye, J. Jones, 2015: Trends and variability in rainon-snow events. Geophys. Res. Lett., 42, 7115-7122, https:// doi.org/10.1002/2015GL065320.

Corripio, J., and J. I. López-Moreno, 2017: Analysis and predictability of the hydrological response of mountain catchments to heavy rain on snow events: A case study in the Spanish Pyrenees. Hydrology, 4, 20, https://doi.org/10.3390/ hydrology 4020020

Devoli, G., D. Tiranti, R. Cremonini, M. Sund, and S. Boje, 2018: Comparison of landslide forecasting services in Piedmont (Italy) and Norway, illustrated by events in late spring 2013 Nat. Hazards Earth Syst. Sci., 18, 1351-1372, https://doi.org/ 10.5194/nhess-18-1351-2018.

Dyrrdal, A. V., K. Isaksen, H. O. Hygen, and N. K. Meyer, 2012: Changes in meteorological variables that can trigger natural hazards in Norway. Climate Res., 55, 153-165, https://doi.org/ $10.3354 / \mathrm{cr} 01125$

- T. Saloranta, T. Skaugen, and H. B. Stranden, 2013: Changes in snow depth in Norway during the period 1961-2010. Hydrol. Res., 44, 169-179, https://doi.org/10.2166/nh.2012.064.

_ , F. Stordal, and C. Lussanaa, 2018: Evaluation of summer precipitation from EURO-CORDEX fine-scale RCM simulations over Norway. Int. J. Climatol., 38, 1661-1677, https:// doi.org/10.1002/joc.5287.

Floyd, W., and M. Weiler, 2008: Measuring snow accumulation and ablation dynamics during rain-on-snow events: Innovative measurement techniques. Hydrol. Processes, 22, 4805-4812, https://doi.org/10.1002/hyp.7142.

Freudiger, D., I. Kohn, K. Stahl, and M. Weiler, 2014: Large-scale analysis of changing frequencies of rain-on-snow events with flood-generation potential. Hydrol. Earth Syst. Sci., 18, 26952709, https://doi.org/10.5194/hess-18-2695-2014.

Garvelmann, J., S. Pohl, and M. Weiler, 2014: Variability of observed energy fluxes during rain-on-snow and clear sky snowmelt in a midlatitude mountain environment. J. Hydrometeor., 15, 1220-1237, https://doi.org/10.1175/JHM-D-13-0187.1.

Hansen, B. B., and Coauthors, 2014: Warmer and wetter winters: Characteristics and implications of an extreme weather event in the high Arctic. Environ. Res. Lett., 9, 114021, https:// doi.org/10.1088/1748-9326/9/11/114021.

Hanssen-Bauer, I., and Coauthors, 2015: Klima i Norge 2100. Norwegian Centre for Climate Services Rep. 2/2015, 204 pp., https://cms.met.no/site/2/klimaservicesenteret/rapporter-ogpublikasjoner/_attachment/6616?_ts=14ff3d4eeb8.

Harr, R. D., 1981: Some consequences and characteristics of snowmelt during rainfall in western Oregon. J. Hydrol., $\mathbf{5 3}$ 277-304, https://doi.org/10.1016/0022-1694(81)90006-8.

Hartmann, D. L., and Coauthors, 2013: Observations: Atmosphere and surface. Climate Change 2013: The Physical Science Basis, T. F. Stocker, et al., Eds., Cambridge University Press, 159-254.
Hurrell, J. W., Y. Kushnir, and G. Ottersen, 2003: An overview of the North Atlantic oscillation. The North Atlantic Oscillation: Climatic Significance and Environmental Impact, Geophys. Monogr., Vol. 134, Amer. Geophys. Union, 1-35, https:// doi.org/10.1029/134GM01.

Irannezhad, M. C., A.-K. Ronkanen, S. Kiani, D. Chen, and B. Kløve, 2017: Long-term variability and trends in annual snowfall/total precipitation ratio in Finland and the role of atmospheric circulation patterns. Cold Reg. Sci. Technol., 143, 23-31, https://doi.org/10.1016/j.coldregions.2017.08.008.

Iversen, E. C., and H. Burningham, 2015: Relationship between NAO and wind climate over Norway. Climate Res., 63, 115134, https://doi.org/10.3354/cr01277.

Jennings, K. S., T. S. Winchell, B. Livneh, and N. P. Molotch, 2018: Spatial variation of the rain-snow temperature threshold across the Northern Hemisphere. Nat. Commun., 9, 1148, https://doi.org/10.1038/s41467-018-03629-7.

Jeong, D. I., and L. Sushama, 2018: Rain-on-snow events over North America based on two Canadian regional climate models. Climate Dyn., 50, 303-316, https://doi.org/10.1007/ s00382-017-3609-x.

Kroczynski, S., 2004: A comparison of two rain-on-snow events and the subsequent hydrologic responses in three small river basins in central Pennsylvania. NOAA Eastern Region Tech. Attachment 2004-04, 21 pp., https://repository.library.noaa.gov/ view/noaa/6656

Liu, Y., L. Wang, W. Zhou, and W. Chen, 2014: Three Eurasian teleconnection patterns: spatial structures, temporal variability, and associated winter climate anomalies. Climate Dyn., 42, 2817-2839, https://doi.org/10.1007/s00382-014-2163-z.

Marks, D., J. Kimball, D. Tingey, and T. Link, 1998: The sensitivity of snowmelt processes to climate conditions and forest cover during rain-on-snow: A case study of the 1996 Pacific Northwest flood. Hydrol. Processes, 12, 1569-1587, https:// doi.org/10.1002/(SICI)1099-1085(199808/09)12:10/11<1569:: AID-HYP682>3.0.CO;2-L

McCabe, G. J., L. E. Hay, and M. P. Clark, 2007: Rain-on-snow events in the western United States. Bull. Amer. Meteor. Soc., 88, 319-328, https://doi.org/10.1175/BAMS-88-3-319.

Messmer, M., J. J. Gómez-Navarro, and C. C. Raible, 2015: 2015: Climatology of $\mathrm{Vb}$ cyclones, physical mechanisms and their impact on extreme precipitation over Central Europe. Earth Syst. Dyn., 6, 541-553, https://doi.org/10.5194/esd-6-541-2015.

Mohr, M., 2009: Comparison of version 1.1 and 1.0 of gridded temperature and precipitation data for Norway. Norwegian Meteorological Institute Met.No Note 19/2009, 44 pp.

Morán-Tejeda, E., J. López-Moreno, M. Stoffel, and M. Beniston, 2016: Rain-on-snow events in Switzerland: Recent observations and projections for the 21st century. Climate Res., 71, 111-125, https://doi.org/10.3354/cr01435.

NOAA/CPC, 2019a: Northern Hemisphere Teleconnection Patterns, North Atlantic Oscillation (updated monthly). National Oceanic and Atmospheric Administration Climate Prediction Center, accessed 4 February 2019, https://www.cpc.ncep.noaa.gov/ data/teledoc/nao.shtml

— 2019b: Teleconnections, Arctic Oscillation (updated monthly). National Oceanic and Atmospheric Administration Climate Prediction Center, accessed 4 February 2019, https://www. cpc.ncep.noaa.gov/products/precip/CWlink/daily_ao_index/ teleconnections.shtml.

,2019c: Northern Hemisphere Teleconnection Patterns, Scandinavia (updated monthly). National Oceanic and Atmospheric Administration Climate Prediction Center, 
accessed 4 February 2019, https://www.cpc.ncep.noaa.gov/ data/teledoc/scand.shtml.

Pomeroy, J. W., X. Fang, and D. G. Marks, 2016: The cold rainon-snow event of June 2013 in the Canadian RockiesCharacteristics and diagnosis. Hydrol. Processes, 30, 2899 2914, https://doi.org/10.1002/hyp.10905.

Pradhanang, S. M., A. Frei, M. Zion, E. M. Schneiderman, T. S. Steenhuis, and D. Pierson, 2013: Rain-on-snow events in New York. Hydrol. Processes, 27, 3035-3049, https://doi.org/ 10.1002/hyp.9864.

Putkonen, J., and G. Roe, 2003: Rain-on-snow events impact soil temperatures and affect ungulate survival. Geophys. Res. Lett., 30, 1188, https://doi.org/10.1029/2002GL016326.

, T. C. Grenfell, K. Rennert, C. Bitz, P. Jacobson, and D. Russell, 2009: Rain on snow: Little understood killer in the north. Eos, Trans. Amer. Geophys. Union, 90, 221-222, https:// doi.org/10.1029/2009EO260002.

Rennert, K. J., G. Roe, J. Putkonen, and C. M. Bitz, 2009: Soil thermal and ecological impacts of rain on snow events in the circumpolar Arctic. J. Climate, 22, 2302-2315, https://doi.org/ 10.1175/2008JCLI2117.1.

Rizzi, J., I. B. Nilsen, J. H. Stagge, K. Gisnås, and L. M. Tallaksen, 2018: Five decades of warming: Impacts on snow cover in Norway. Hydrol. Res., 49, 670-688, https://doi.org/10.2166/ nh.2017.051.

Roald, L. A., 2008: Rainfall floods and weather patterns. Norwegian Water Resources and Energy Directorate Rep. 14-2008, 45 pp., http://publikasjoner.nve.no/oppdragsrapportA/2008/ oppdragsrapportA2008_14.pdf.

, 2013: Flom i Norge. Tom and Tom, 184 pp.

— 2015 : Flommen på Østlandet i mai 2013. Norwegian Water Resources and Energy Directorate Rep. 21-2015, 65 pp., http://publikasjoner.nve.no/rapport/2015/rapport2015_21.pdf.

Rössler, O., P. Froidevaux, U. Börst, R. Rickli, O. Martius, and R. Weingartner, R., 2014: Retrospective analysis of a nonforecasted rain-on-snow flood in the Alps-A matter of model limitations or unpredictable nature? Hydrol. Earth Syst. Sci., 18, 2265-2285, https://doi.org/10.5194/hess-18-2265-2014.

Saloranta, T. M., 2012: Simulating snow maps for Norway: Description and statistical evaluation of the seNorge snow model. Cryosphere, 6, 1323-1337, https://doi.org/10.5194/ tc-6-1323-2012.

, 2014: New version (v.1.1.1) of the seNorge snow model and snow maps for Norway. Norwegian Water Resources and Energy Directorate Rep. 6-2014, 34 pp., http://publikasjoner.nve.no/ rapport/2014/rapport2014_06.pdf.

Sen, P. K., 1968: Estimates of the regression coefficient based on Kendall's tau. J. Amer. Stat. Assoc., 63, 1379-1389, https:// doi.org/10.1080/01621459.1968.10480934.

Singh, P., G. Spitzbart, H. Hübl, and H. W. Weinmeinster, 1997: Hydrological response of snowpack under rain-on-snow events: A field study. J. Hydrol., 202, 1-20, https://doi.org/10.1016/ S0022-1694(97)00004-8.

Spearman, C., 1904: The proof and measurement of association between two things. Amer. J. Psychol., 15, 72-101, https:// doi.org/10.2307/1412159.

Stimberis, J., and C. M. Rubin, 2011: Glide avalanche response to an extreme rain-on-snow event, Snoqualmie Pass, Washington, USA. J. Glaciol., 57, 468-474, https://doi.org/10.3189/ 002214311796905686.
Sui, J., and G. Koehler, 2001: Rain-on-snow induced flood events in southern Germany. J. Hydrol., 252, 205-220, https://doi.org/ 10.1016/S0022-1694(01)00460-7.

Surfleet, C. G., and D. Tullos, 2013: Variability in effect of climate change on rain-on-snow peak flow events in temperate climate. J. Hydrol., 479, 24-34, https://doi.org/10.1016/ j.jhydrol.2012.11.021.

Theil, H., 1950: A rank-invariant method of linear and polynomial regression analysis. Indag. Math., 12, 85-91.

Thompson, D. W. J., and J. M. Wallace, 1998: The Arctic oscillation signature in wintertime geopotential height and temperature fields. Geophys. Res. Lett., 25, 1297-1300, https://doi.org/ 10.1029/98GL00950.

Trenberth, K. E., 1999: Conceptual framework for changes of extremes of the hydrological cycle with climate change. Climatic Change, 42, 327-339, https://doi.org/10.1023/A: 1005488920935.

Trubilowicz, J. W., and R. D. Moore, 2017: Quantifying the role of the snowpack in generating water available for run-off during rain-on-snow events from snow pillow records. Hydrol. Processes, 31, 4136-4150, https://doi.org/10.1002/ hyp.11310.

Tveito, O. E., I. Bjørdal, A. O. Skjelvåg, and B. Aune, 2005: A GIS based agro-ecological decision system based on gridded climatology. Meteor. Appl., 12, 57-68, https://doi.org/10.1017/ S1350482705001490.

Uvo, C. B., 2003: Analysis and regionalization of northern European winter precipitation based on its relationship with the North Atlantic Oscillation. Int. J. Climatol., 23, 1185-1194, https://doi.org/10.1002/joc.930.

Vikhamar-Schuler, D., K. Isaksen, and J. E. Haugen, 2016: Changes in winter warming events in the Nordic Arctic region. J. Climate, 29, 6223-6244, https://doi.org/10.1175/ JCLI-D-15-0763.1.

Vormoor, K., D. Lawrence, L. Schlichting, D. Wilson, and W. K. Wong, 2016: Evidence for changes in the magnitude and frequency of observed rainfall vs. snowmelt driven floods in Norway. J. Hydrol., 538, 33-48, https://doi.org/ 10.1016/j.jhydrol.2016.03.066.

Wayand, N. E., J. D. Lundquist, and M. P. Clark, 2015: Modeling the influence of hypsometry, vegetation, and storm energy on snowmelt contributions to basins during rain-on-snow floods. Water Resour. Res., 51, 8551-8569, https://doi.org/10.1002/ 2014WR016576.

Westermann, S., J. Boike, M. Langer, T. V. Schuler, and B. Etzelmüller, 2011: Modelling the impact of wintertime rain events on the thermal regime of permafrost. Cryosphere, $\mathbf{5}$, 945-959, https://doi.org/10.5194/tc-5-945-2011.

Würzer, S., T. Jonas, N. Wever, and M. Lehning, 2016: Influence of initial snowpack properties on runoff formation during rain-on-snow events. J. Hydrometeor., 17, 1801-1815, https:// doi.org/10.1175/JHM-D-15-0181.1.

Ye, H., D. Yang, and D. Robinson, 2008: Winter rain on snow and its association with air temperature in northern Eurasia Hydrol. Processes, 22, 2728-2736, https://doi.org/10.1002/ hyp.7094.

Yue, S., and P. Pilon, 2004: A comparison of the power of the $t$ test, Mann-Kendall and bootstrap tests for trend detection. Hydrol. Sci. J., 49, 21-37, https://doi.org/10.1623/hysj.49.1.21.53996. 